Old Dominion University

ODU Digital Commons

Counseling \& Human Services Theses \&

Dissertations

Counseling \& Human Services

Spring 2011

\title{
Attitudes of Counselors Regarding Ethical Situations Encountered by In-Home Counselors
}

Justin Douglas Lauka

Old Dominion University

Follow this and additional works at: https://digitalcommons.odu.edu/chs_etds

Part of the Applied Ethics Commons, Counseling Commons, and the Counseling Psychology Commons

\section{Recommended Citation}

Lauka, Justin D.. "Attitudes of Counselors Regarding Ethical Situations Encountered by In-Home Counselors" (2011). Doctor of Philosophy (PhD), Dissertation, Counseling \& Human Services, Old Dominion University, DOI: $10.25777 /$ jqkc-3m78

https://digitalcommons.odu.edu/chs_etds/74

This Dissertation is brought to you for free and open access by the Counseling \& Human Services at ODU Digital Commons. It has been accepted for inclusion in Counseling \& Human Services Theses \& Dissertations by an authorized administrator of ODU Digital Commons. For more information, please contact digitalcommons@odu.edu. 


\section{ATTITUDES OF COUNSELORS}

REGARDING ETHICAL SITUATIONS

ENCOUNTERED BY IN-HOME COUNSELORS

by

Justin Douglas Lauka

B.A., May 2004, Michigan State University

B.A., May 2005, Michigan State University M.A., May 2008, Regent University

A Dissertation Submitted to the Faculty of Old Dominion University in Partial Fulfillment of the Requirement for the Degree of

DOCTOR OF PHILOSOPHY

COUNSELOR EDUCATION AND SUPERVISION

OLD DOMINION UNIVERSITY

May 2011

Approvedp $b y:$

Theodore B. Remley, Jr. (Chair)

Christine Ward (Mémber)

Dana Burnett (Member) 


\author{
ABSTRACT \\ ATTITUDES OF COUNSELORS REGARDING ETHICAL SITUATIONS \\ ENCOUNTERED BY IN-HOME COUNSELORS \\ Justin Douglas Lauka \\ Old Dominion University, 2011 \\ Chair: Dr. Theodore P. Remley
}

This survey study explored the attitudes of in-home and outpatient counselors in Virginia regarding ethical situations encountered by in-home counselors. Differences in responses were examined across several variables to identify any relationships among those constructs that are salient to in-home counseling and ethics. Of 108 participants, no significant differences were found between the two groups. One variable was found to predict counselors' responses: the percent counselors provide counseling services compared to case management. The item seen as most ethical involved telling a client to apply for needed services, surprising, given its directive nature that runs counter to the counseling profession. The item seen as least ethical involved providing counseling outside of one's level of competence. Considering this along with several open-ended comments expressing concern over unqualified and under-educated in-home counselors provides important implications for counselors, supervisors, and educators and gives direction for future research. 


\section{ACKNOWLEDGEMENTS}

There truly are so many people to thank for helping me along this journey that led to the successful completion of my doctoral program. First I want to thank my lovely wife Bri, who had the patience and fortitude to continue loving and serving me in spite of the self-absorbed moments that this program required of me. You have been nothing short of a miracle in my life, and the timing of our marriage must have been ordained, since you were there when I needed you most during the tumultuous period of completing this dissertation.

The guidance and encouragement of the ODU faculty has been crucial to my perseverance in this program. Thank you especially Dr. Remley, Dr. Danica Hays, Dr. Christine Ward, Dr. George Pratt, and Dr. Dana Burnett in the vital roles that you played in sustaining me throughout this program. Dr. Remley, I cannot emphasize enough how much your support and mentorship has meant to me throughout my time at ODU. You always had the exact words that I needed, providing wisdom and assurance that I had the abilities and internal resources to succeed. Once again, thank you. Danica, thank you for the much needed support at the counseling clinic where your wisdom and influence both assisted in creating an efficient training clinic that I was proud to oversee. Your dependability and expedience in resolving matters was always something that I marveled at. Dr. Pratt, I will never forget our supervision sessions, where I would often come with both excitement and trepidation. You have masterfully balanced the art of challenging with support in your sessions, facilitating growth in myself as a supervisor and administrator. Thank you for your kindness, wisdom, and demand for excellence from me. 
Thank you Dr. Ward and Dr. Burnett for being on my dissertation committee. I have appreciated both of your timely and constructive feedback throughout this daunting process. Dr. Ward, thank you for your patience and gentle instruction with me regarding my methodology. Dr. Burnett I appreciate your willingness to be a part of this committee, as well as the value feedback and your sincere interest in my topic.

I also would like to thank my family, particularly my mom who has been the quintessential exemplification of compassion and self-sacrifice. I am so thankful for the love that you have demonstrated to me and the values that you have instilled in me. I have no doubt that it was your influence that has led me to the counseling profession. I also want to thank my brothers and my sister, Jeshua, Tanner, Brady, and Genny. You all have loved me and influenced me in unique ways, which I am forever thankful for. I am grateful for the roles that you have played in my life that have assisted in shaping me into the man I am today.

Lastly, I want to thank above all my God and Savior, who has ordained and called me into this profession. Your ways are truly higher than mine, and I would never have planned the course of events to transpire that brought me here. I am forever thankful that you have led me and guided me to where I am today, and can only hope that I will be a faithful steward of the abilities and talents you have given me. 
TABLE OF CONTENTS

$\begin{array}{rlll}20 & \text { Page }\end{array}$

LIST OF TABLES. .............................................................

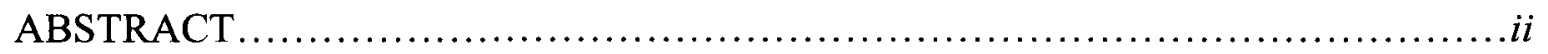

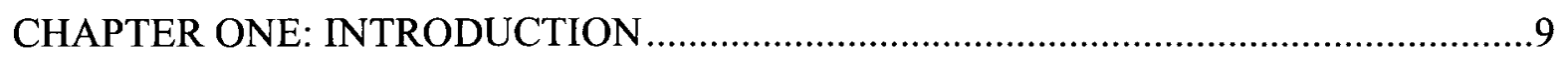

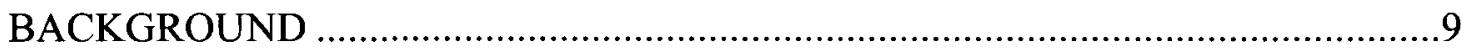

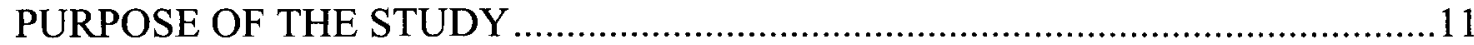

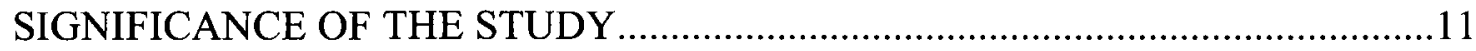

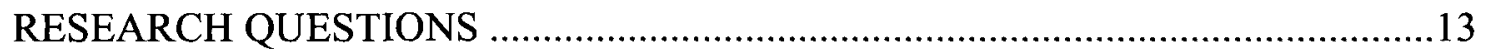

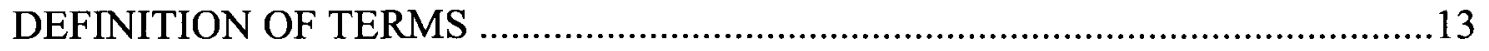

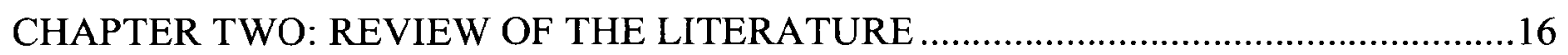

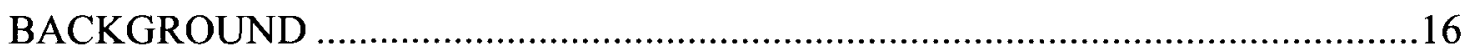

IN-HOME COUNSELING: A WIDE SPECTRUM OF SERVICES ........................19

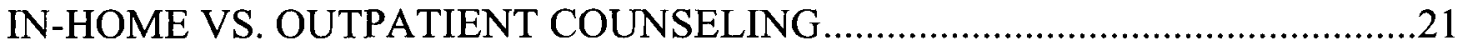

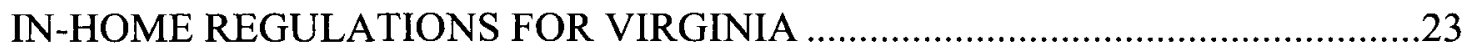

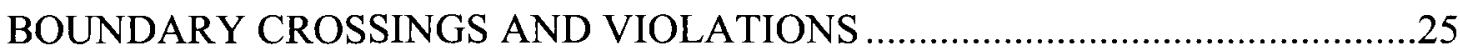

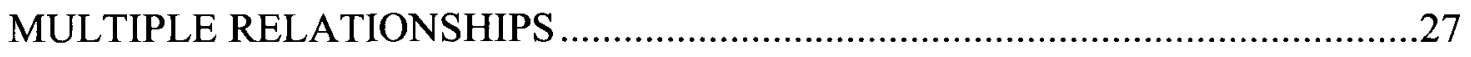

ACA CODE OF ETHICS AND IN-HOME COUNSELING .................................29

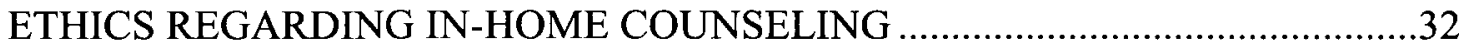

ETHICAL SURVEYS IN MENTAL HEALTH ……..............................................35

ETHICAL SURVEYS FOR IN-HOME COUNSELING ..........................................

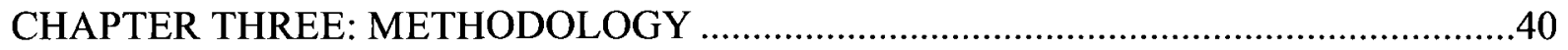

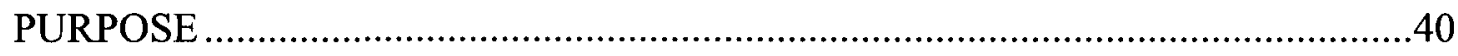

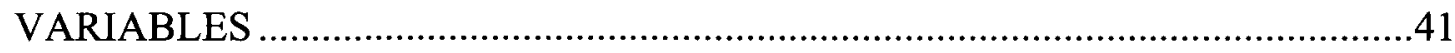

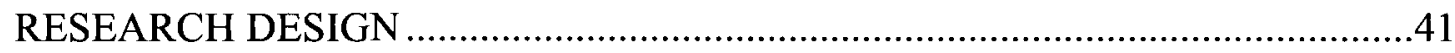

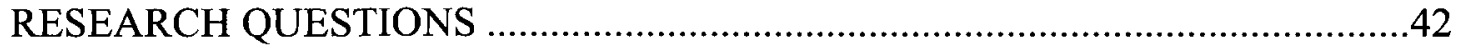

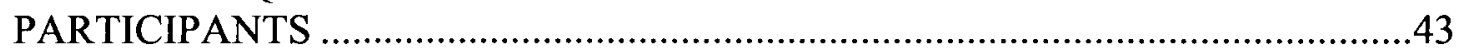

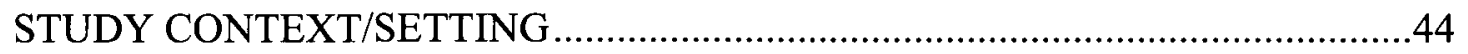

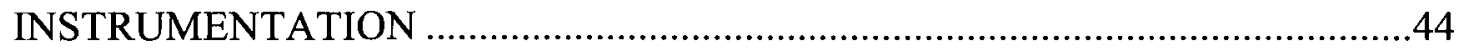

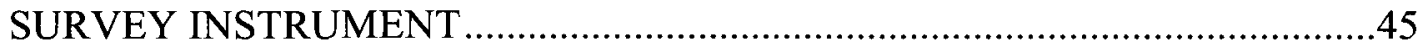

ITEM GENERATION AND CONTENT VALIDATION ...................................45

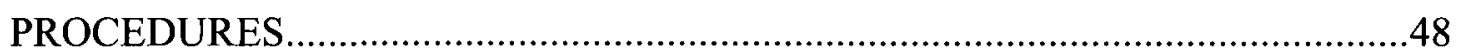

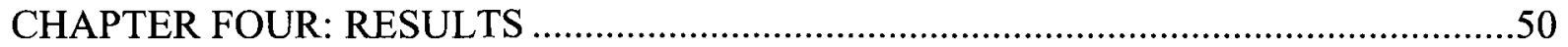

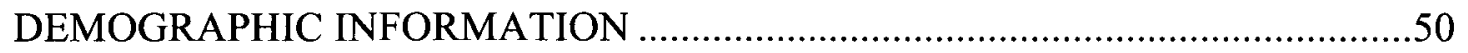

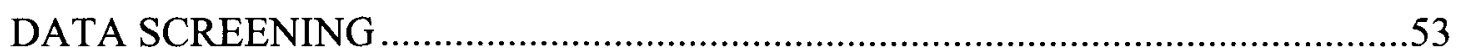

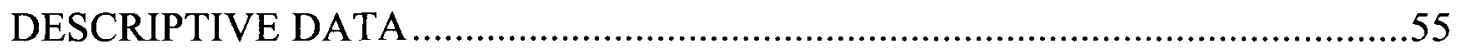

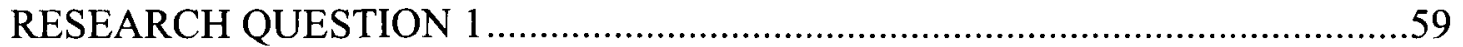

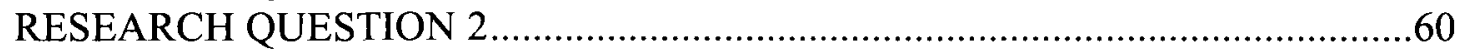

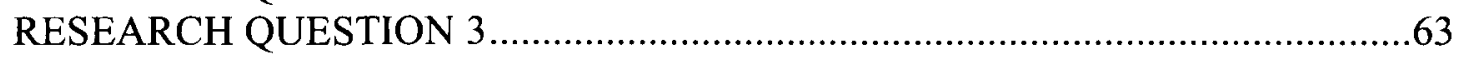




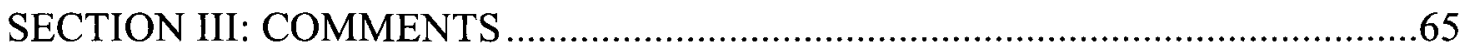

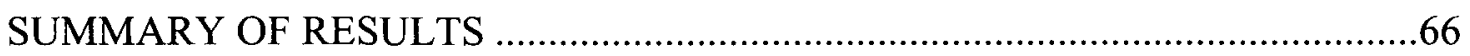

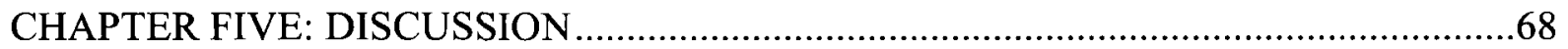

DISCUSSION OF FINDINGS FROM DESCRIPTIVE DATA ……...................69

DISCUSSION OF FINDINGS FROM RESEARCH QUESTION 1 ......................73

DISCUSSION OF FINDINGS FROM RESEARCH QUESTION 2 ........................74

DISCUSSION OF FINDINGS FROM RESEARCH QUESTION $3 \ldots \ldots \ldots \ldots \ldots \ldots \ldots \ldots . . .75$

DISCUSSION OF FINDINGS FROM COMMENTS ON SECTION III...................75

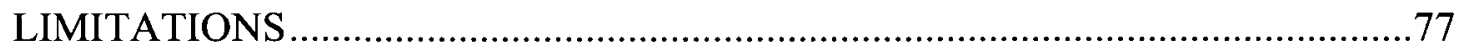

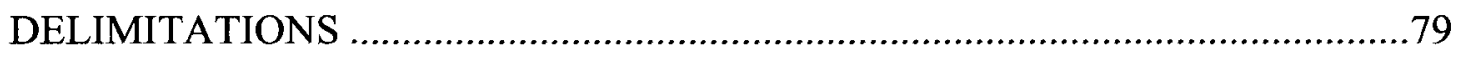

IMPLICATIONS FOR COUNSELORS, EDUCATORS, AND SUPERVISORS ...79

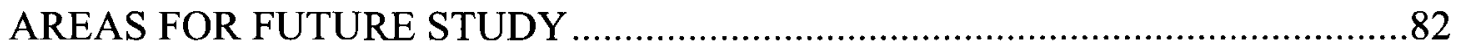

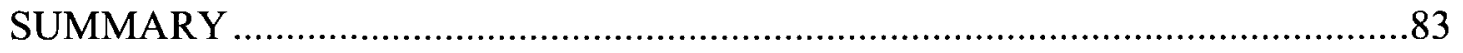

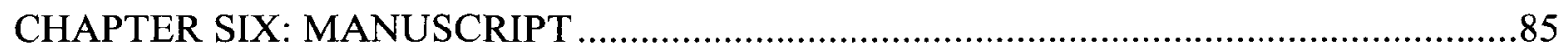

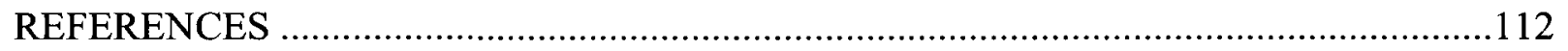

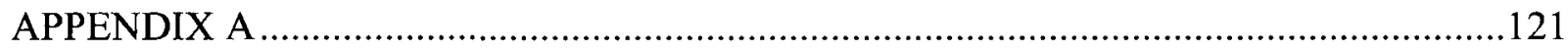

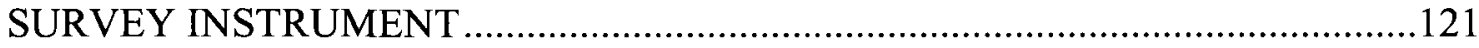

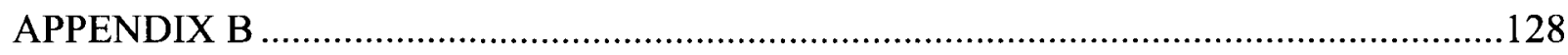

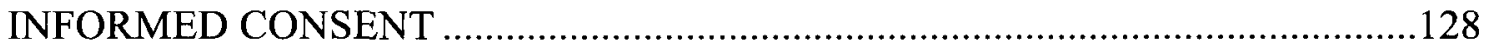

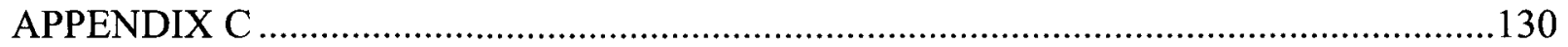

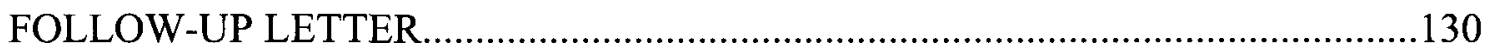

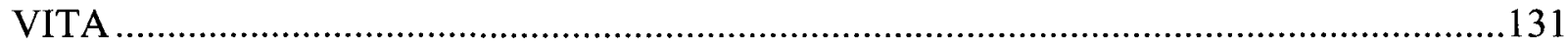




\section{LIST OF TABLES}

\section{Page}

Table 1 Degrees Earned and Licenses and Certifications Held ................................52

Table 2 Percentage of Counseling Compared to Case Management .............................53

Table 3 Attitudes of Counselors Regarding Ethical Situations ..................................56

Table 4 Summary of Multiple Linear Regression Predicting Counselors' Attitudes About Ethical Situations Typically Encountered by In-Home Counselors

Table 5 Summary of Multiple Linear Regression Predicting In-Home Counselors Attitudes About Ethical Situations Typically Encountered by In-Home Counselors 


\section{CHAPTER ONE: INTRODUCTION}

\section{Background}

In recent years the field of mental health has witnessed the proliferation of counseling services provided within the homes of clients (Adams \& Maynard, 2000; Wasik \& Roberts, 1994). Contributing to this demand for in-home counseling services was the passage of the Adoption Assistance and Child Welfare Act of 1980, which emphasized the maintenance of intact and safe families, as opposed to the practice that was prevalent at the time of placing children into foster homes (Christensen, 1995; Nelson, Landsman, \& Deutelbaum, 1990). Flowing from this 1980 law has been a rapid emergence of family preservation services, where clinicians provide concrete services, encouraging family empowerment while attempting to keep children in the original household; thus hopefully providing the least restrictive treatment possible in a costeffective manner (Wells \& Biegel, 1992).

Today, in-home counseling services are provided by mental health professionals from various backgrounds to treat a wide array of presenting problems, including both mood and psychotic disorders (Kalucy et al., 2003), antisocial behavior (Curtis, Ronan, \& Borduin, 2004), substance abuse (Gruber \& Fleetwood, 2004), and diabetes (Harris \& Mertlich, 2003). While clients most commonly treated are children and adolescents who possess emotional and behavioral disturbances (Liddle et al., 2005; Mattek et al., 2010, Mosier et al, 2001), in-home counseling has also been shown to be a promising treatment with families (Curtis, Ronan, \& Borduin, 2004; Liddle et al., 2005; Yorgason et al., 2005) and older persons (Cabin, 2010; Maxfield \& Segal, 2008). Typically, the 
population of clients who receive in-home counseling are referred to as multichallenged or multistressed families, and possess multiple problems that are chronic and severe in nature (Adams \& Maynard, 2000; Lawick \& Bom, 2008). In-home counseling has been found to be a cost effective treatment (Crane et al, 2003) reducing hospitalizations and out-of-home placements of children (Yorgason, 2005). Additionally, in-home counseling offers several distinct advantages over traditional outpatient counseling including an increased attendance rate (Slesnick \& Prestopnick, 2004) and greater treatment engagement (Thompson et al, 2007). By providing counseling services to those clients who would either not be willing or able to receive counseling in an office setting, the counseling field is operating as advocates to the vulnerable and marginalized members of society.

Along with the benefits of this rising modality come challenges as well. More specifically, the literature has documented concerns in safety (Christensen, 1995), environmental distractions (Worth, 2004), counselor training and preparation (Adams \& Maynard, 2000; Stinchfield, 2004), and supervision (Lawson, 2005). All of these items point to the overarching ethical and boundary-related issues that have recently been given considerable attention (Christensen, 1995; Knapp \& Slattery, 2004; Lawson, 2005; Thomas et al., 1999; Woodford, 1999). However, the exact nature of these ethical issues encountered by counselors has not been adequately captured, requiring further scrutiny. 


\section{Purpose of Study}

The primary purpose of this study was to explore the attitudes of in-home and outpatient counselors in the commonwealth of Virginia regarding ethical situations typically encountered by in-home counselors. More specifically, this study sought to determine whether any differences exist in responses by counseling modality (in-home, outpatient). The independent variables utilized in the study were: gender of counselor, mental health field, highest degree obtained, employment status, years of experience as an in-home counselor, years of experience as a mental health professional, license and certifications, and percentage of work providing in-home counseling compared to case management. These were examined to determine if they were predictors of in-home and outpatient counselors' attitudes about ethical situations typically encountered by in-home counselors. These variables were also examined to determine if they predicted, exclusively, in-home counselors' attitudes about ethical situations. Currently, there is no research that captures the attitudes of in-home counselors along the entire spectrum of training and education levels. Previous research studies have been conducted using professional association directories (Roberts, 2006; Worth, 2004), which generally contain members with more advanced degrees than this study planned to include.

\section{Significance of Study}

This study has importance because of the highly intimate setting that working in a client's home provides. Families generally engage in very personal activities, conversations, and experiences within the household. Coupling the home environment with the very intimate nature of the counseling relationship can potentially result in 
emotionally charged and problematic situations (Reiter, 2000; Stinchfield, 2004). Pope and Vasquez (2007) noted the inherent power that mental health professionals possess in the counseling relationship, eliciting profound feelings from the client of love, rejection, shame, guilt, approval, dependence, and panic. While these emotions may serve a therapeutic purpose at times, a counselor eliciting these emotions in a client's home may prove to be a foundation for unethical situations to occur. Furthermore, because the practice of in-home counseling is in its infancy stage, there has not been a considerable amount of research conducted on this modality (Thomas, McCollum, \& Snyder, 1999), particularly regarding ethical challenges.

The minimal requirements and qualifications for in-home counselors presents additional concerns. While most in-home counselors possess at least a bachelor's degree, the Medical Assistance Programs (Medicaid), which provide reimbursement for in-home services, places the minimum education requirement of an associate's degree with three years experience (DMAS, 2008). A recent amendment to the Department of Medical Assistance Services manual (DMAS, 2010) lowers the requirements further for in-home counseling. The DMAS manual indicates that a supervisor of an in-home counselor no longer has to be a licensed mental health professional, but can be license-eligible (DMAS, 2010). The overall lack of required education and training of in-home counselors, combined with the very challenging population of clients that is commonly served in their homes, along the unique environment in which clients are served (in their homes rather than in professional offices), may create conditions in which unethical and dangerous situations could easily occur. 


\section{Research Questions}

The general research question explored was: What is the difference, if any, between in-home and outpatient counselors' attitudes about ethical situations typically encountered by in-home counselors? The second question was: To what degree do the following variables predict in-home and outpatient counselors' attitudes about ethical situations typically encountered by in-home counselors; sex of counselor, discipline, education, employment status, years of experience as an in-home counselor, years of experience as a mental health professional, licenses and certifications held, and percentage of work providing in-home counseling compared to case management? The third research question was: To what degree do the following variables predict in-home counselors' attitudes about ethical situations typically encountered by in-home counselors; sex of counselor, discipline, education, employment status, years of experience as an in-home counselor, years of experience as a mental health professional, licenses and certifications held, and percentage of work providing in-home counseling compared to case management?

\section{Definitions}

Case management service: "Assisting individuals and their families to access services and supports that are essential to meeting their basic needs identified in their individualized service plan, which include not only accessing mental health services but also any medical, nutritional, social, educational, vocational and employment, housing, economic assistance, transportation, leisure and recreational, legal, and advocacy services 
and supports that the individual needs to function in the community setting" (DBHDS, 2008, p. 4).

Boundary: The confines of an appropriate relationship developed by a mental health professional with a client (Gutheil \& Gabbard, 1998).

Boundary crossing: "A benign variant where the ultimate effect of the deviation from the usual verbal behavior may be to advance the therapy in a constructive way that does not harm the patient" (Gutheil \& Gabbard, 1998, p. 410)

Boundary violation: "When a transgression of a relationship boundary is clearly harmful to or exploitative of a client. The harm may range from wasting time and therapeutic opportunity to inflicting severe trauma" (Gutheil \& Gabbard, 1998, p. 410).

In-home counseling: "Family preservation interventions for children and adolescents who have a serious emotional disturbance or are at risk of having one. Services are usually time limited and are provided typically in the residence of an individual who is at risk of being moved to out-of-home placement or who is being transitioned back home from an out-of-home placement. These services include crisis treatment; individual, and family counseling; life, parenting, and communication skills; case management activities and coordination with other services; and emergency response" (DMAS, 2010, p. 6).

License Eligible Mental Health Professional: An individual who has completed his or her graduate degree and is under the direct supervision of an individual licensed under the law of a state. This individual must be working towards licensure and usually must be registered with the appropriate licensing board (DMAS, 2010). 
Licensed Mental Health Provider (LMHP): “A physician, licensed clinical psychologist, licensed professional counselor, licensed clinical social worker, licensed marriage and family therapist, or a psychiatric clinical nurse specialist" (DMAS, 2010, p. $6)$.

Qualified Mental Health Professional (QMHP): "A clinician in the human services field who is trained and experienced in providing psychiatric or mental health services to individuals who have a psychiatric diagnosis" (DMAS, 2010, p. 7).

Slippery slope phenomenon: When a seemingly minor boundary violation progresses from a helpful professional relationship to a harmful or exploitive one (Gutheil \& Gabbard, 1998). 


\section{CHAPTER TWO}

\section{REVIEW OF THE LITERATURE}

\section{Background}

Although relatively new to the field of counseling, in-home services have been consistently used by social workers since the beginning of the $20^{\text {th }}$ century (Woodford, 1999). Termed friendly visitors, these social workers placed an emphasis on coordinating services for families and mobilizing networks of helpers for the clients (Woodford). However, it wasn't until the 1950s and 1960s that in-home services began to take the shape of actual counseling services by applying theoretical frameworks to this practice (Woodford).

Catapulting the need and practice of this modality further may be attributed in part to the passage of the Adoption Assistance and Child Welfare Act of 1980, Public Law 96-272, which encouraged the effort to keep children in their homes as opposed to foster care, group homes, or adoption (Well \& Biegel, 1990). The premise behind this law was that the optimal method to protect a child was to strengthen the family that the child relied upon (Mosier et al., 2001). Legislators further concluded that the removal of children from their home was expensive and inefficient, requiring an alternative approach (Lawson, 2005). This movement led to the creation of a new wave of child and family services.

Commonly known as family preservation services, these programs, while varied across states and counties (Bagdasaryan, 2005), share several similarities. Many of these programs provide both case management and counseling services to families several 
times per week, one to four hours at a time (Woodford et al., 2006). Clients are allowed access to counselors 24 hours a day, seven days a week for crisis calls, (Greeson et al., 2009) while commonly applying a family systems theoretical approach (Bagdasaryan). Additionally, counselors may provide psychoeducation and skill building for parents in order to effectively manage conflict, thus keeping families intact (Cortes, 2004).

This movement emphasized the value of keeping children connected with their parents while helping families become self-sufficient and providing community-based services in the least restrictive environments (Woodford et al., 2006). The recipients of these services were derived from three main components in the public sector: the population of juvenile delinquents, abused or neglected children, and children with severe psychiatric or emotional disorders (Mosier et al., 2001). Family preservation services have proven to be crucial to the child welfare system and currently serve as one of the largest prevention services within this system (Denby \& Curtis, 2003).

In recent years, there has been a growing body of evidence in support of the efficacy of including the entire family in counseling, particularly in the home setting (Liddle et al., 2001; Madsen, 1999). In-home counseling has been shown to increase both attendance and participation of adolescents and their families in counseling sessions in comparison with an outpatient setting (Slesnick \& Prestopnick, 2004; Speck, 1964). This counseling modality is especially amenable for impoverished families who lack transportation or childcare (Mattek, Jorgenson, \& Fox, 2010). Mosier et al. (2001) measured the outcomes of 104 in-home clients at a large multistate organization in the Rocky Mountain Region. The results of their study suggested that in-home treatment was effective in significantly reducing behavioral and emotional problems in children and 
adolescents (Mosier et al., 2001). In-home counseling services have also been shown to lessen the number of out-of-home placements of children, lower the risk of hospitalizations, and reduce maladaptive behaviors and emotions associated with the presenting problems of the client (Yorgason, 2005).

Because the home environment is laden with a plethora of information that a counselor is normally not privy to, in-home counseling has been found to be a strong diagnostic tool to gather information and make assessments (Christensen, 1995). In-home counselors are also afforded the clear advantage of "ongoing visual observation of the atmosphere, values and investments" (Christensen, p. 307). Furthermore, the in-home counselor is able to learn about the family's cultural patterns, socioeconomic level, and interaction patterns, which may lead to quicker information gathering and an expedited treatment process (Reiter, 2000). This modality of counseling has also been demonstrated to increase therapeutic alliance, compliance with treatment requirements, and engagement (Lay, Blanz, \& Schmidt, 2001). Reiter (2000) purported that "when entering the client's home, the home-based therapist sends a message to the family that they are meaningful and their family world is important" (p. 29). Finally, in-home counseling has been found to be effective in preventing child abuse and neglect in several countries, including the United States, Ireland, and some European countries (Huston \& Armstrong, 1999).

In-home counseling services are currently provided by mental health professionals from various backgrounds to treat a wide array of presenting problems, including both mood and psychotic disorders (Kalucy et al., 2003), antisocial behavior (Curtis, Ronan, \& Borduin, 2004), substance abuse (Gruber \& Fleetwood, 2004), and 
diabetes (Harris \& Mertlich, 2003). While clients most commonly treated are children and adolescents who possess emotional and behavioral disturbances (Mattek et al., 2010, Mosier et al., 2001; Liddle et al., 2005), in-home counseling has also been shown to be a promising treatment with families (Curtis, Ronan, \& Borduin; Liddle et al., 2005; Yorgason et al., 2005) and older persons (Cabin, 2010; Kang-Yi \& Gellis, 2010; Maxfield \& Segal, 2008). Kang-Yi and Gellis conducted a meta-analysis on communitybased interventions for depression with older persons with heart disease. The researchers found three experimental studies where home-based interventions were found to be significantly superior over control groups in reducing depressive symptoms (Kang-Yi \& Gellis).

While various titles have been used to describe this modality—such as homebased services, in-home counseling, intensive in-home therapy, home-visiting, familybased programs, or family preservation services (Cortes, 2004)—for the purpose of consistency, the term in-home counseling will be used in this research study.

\section{In-Home Counseling: A Wide Spectrum of Services}

In-home counseling takes a significant departure from outpatient counseling in the wide spectrum of services that counselors perform. In-home counseling services can be broadly defined as "counseling and case management services provided to families that have a child at risk for removal from the home" (Lawson \& Foster, 2005, p. 153). In the state of Virginia, the Department of Behavioral Health and Developmental Services (DBHDS) provides a more thorough definition of intensive in-home services that falls under Article 12 VAC 35-105-20 in the Code of Virginia: 
Intensive in-home service means family preservation interventions for children and adolescents who have or are at-risk of serious emotional disturbance, including such individuals who also have a diagnosis of mental retardation. Services are usually time limited provided typically in the residence of an individual who is at risk of being moved to out-of-home placement or who is being transitioned back home from an out-of-home placement. These services include crisis treatment; individual and family counseling; life, parenting, and communication skills; case management activities and coordination with other services; and emergency response. (p. 4)

Snyder and McCollum (1999) noted that in-home counseling services can range from providing manual labor, such as babysitting and transportation, to actual therapeutic and counseling services. Adams and Maynard (2000) described interventions that may be unique to an in-home counselor, which include intervening when observing that a home has not been baby proofed and there are hazardous materials blatantly scattered throughout the house. Mosier et al. (2001) illuminated this further, stating that the delivery of in-home counseling is quite varied and can include the following components: "assessment, crisis intervention, case management, collateral contacts with other treating clinicians, school contacts, unplanned home visits, client-family education on behavior management strategies, delivery of reinforcements as goals are met, and development of social support for the family outside of the agency" (p. 56). 


\section{In-Home vs. Outpatient Counseling}

In-home counseling stands apart from counseling in an outpatient setting in the different treatment approaches that are utilized, the unique population that this modality serves, the unique demands placed upon clinicians (Mattek, Jorgenson, \& Fox, 2010), the type of training, and the pace of change that can be expected from the in-home clientele (Adams \& Maynard, 2000; Snyder \& McCollum, 1999).

In comparison with traditional outpatient counseling, in-home is generally provided to families who have a combination of tangible needs in addition to the presenting problem of the identified client (Lawson \& Foster, 2005). This type of family has been commonly known as multi-stressed and is defined as "usually high stressed, and having multiple problems involving drug/alcohol abuse, domestic violence, truancy, financial difficulties, assault/battery, depression, and other mental illnesses" (Adams \& Maynard, 2000, p. 49). Several researchers have noted the severity of behavioral and emotional problems of in-home clients (Mattek, Jorgenson \& Fox, 2010; Lawick \& Bom, 2008; Mosier et al., 2001). Lawick and Bom (2008) noted that multi-stressed families generally possess stress factors in all major facets of their lives, which may contribute to a sense of distrust to the outside world—including helping professionals.

As noted earlier, services provided through most in-home counseling models deviate dramatically from traditional outpatient models in regard to duration, intensity, location, and frequency of counseling sessions. In-home counseling is a more intensive service, as sessions can range from two to three times per week, one to four hours at a time (Reiter, 2000; Speck, 1964; Woodford et al., 2006). This stands in stark contrast to meeting with a client in an office once per week for a 45-50 minute counseling session. 
While some forms of office-based counseling may last years, in-home counseling is generally limited to 3 to 6 months (Woodford et al., 2006). The physical location of a counseling session may vary from session to session with in-home counseling. In-home counseling sessions may be held in living rooms, kitchens, bathrooms, dining rooms, basements, bedrooms, or outside the home in a park or yard (Reiter, 2000, Speck, 1964). Speck noted that occasionally client and counselors shift to multiple rooms in a single session.

Further separating in-home counseling from outpatient counseling are the multiple levels of focus to which in-home counseling extends. Yorgason (2005) stated that in-home counseling treatment not only targets the individual client, but the immediate family, extended family, familial interactions within the community, and larger societal factors as well. Furthermore, in-home counselors typically work in concert with various other agencies (e.g., schools, protective services, and courts) that may be assisting the family concurrently (Adams \& Maynard, 2000).

It has been argued that in-home counseling services are more challenging for a counselor than an outpatient setting due to the highly unstructured environment, the greater ambiguity in roles and boundaries, the multi-stressed client population served, and the numerous simultaneous demands on the counselors both cognitively and interpersonally (Lawson \& Foster, 2005; Mosier et al., 2001; Yorgason et al., 2005). Slattery (2005) noted that the less goal-oriented nature of in-home counseling coupled with the more personal context of working in one's home can make it a much more confusing process for the client and counselor to navigate. In addition, those providing in-home counseling have expressed concern over their safety, noting that the home 
environment is particularly distracting and oftentimes clients are located in dangerous neighborhoods (Christensen, 1995; Cottrell, 1994; Wasik \& Bryant, 2001; Woodford, Bordeau, \& Alderfer, 2006).

\section{In-Home Regulations for Virginia}

In the state of Virginia, intensive in-home counseling services often seek reimbursement through the Virginia Medical Assistance Program (Medicaid), a program designed to provide medical and health care to the indigent and needy citizens of Virginia (DMAS, 2010). Congress created the national initiative Medical Assistance Program in 1965 as Title XIX of the Social Security Act, providing grants for each state's individual Medical Assistance Program. Among the covered services are intensive in-home services for children and adolescents and home health services (DMAS, 2010).

While Medicaid sets a minimum requirement, the program also mandates that providers be licensed by the Department of Behavioral Health and Developmental Services (DMAS, 2010). Under the Virginia Department of Behavioral Health and Developmental Services (BHDS), in order to become a licensed provider of in-home counseling services, the staff providing the services must be either a Qualified Mental Health Professional (QMHP) or a Licensed Mental Health Professional (LMHP) with a minimum education of a bachelor's degree and one year of experience (DBHDS, 2010). What is unclear are the distinctions between the services that a QMHP is allowed to provide and an LMHP. According to BHDS, a QMHP is allowed to provide counseling to families, which is defined as "guidance, advice, and psychoeducational services" (BHDS, 2010). In contrast, "when therapy is required to address the clinical issues, the intensive 
in-home program is responsible for either providing therapy or arranging an outside therapist. All therapy must be provided by a LMHP or Master's level license eligible provider" (BHDS, 2010).

The terms counseling and therapy can be both confusing and misleading. The term counseling is defined differently by the Virginia Board of Counseling (2010) and the American Counseling Association (1997). According to Chapter 35 of Title 54.1 of the Code of Virginia, counseling encompasses conducting assessments, diagnosing, creating treatment goals and objectives, planning, implementing treatment plans, and using interventions to facilitate human development as well as identifying and remediating mental, emotional, or behavioral disorders that interfere with one's mental health. The American Counseling Association (ACA) in the definition of counseling includes the application of psychological or human developmental principles, while using cognitive, affective, behavioral, or systematic interventions, as well as addressing pathology (1997).

Similarly, Gladding (1996) made a distinction between the terms counseling and guidance, with guidance being the process of helping people who are making important decisions, and counseling playing a more proactive role in facilitating change. The discrepancy between what DMAS and BHDS define as actual counseling and what the Virginia Board of Counseling and the American Counseling Association define as counseling can be quite problematic. Additionally, these varied definitions of counseling and therapy can bring about a disservice to clients, who may be under the assumption that they are to receive actual counseling services when in fact what they receive will be advice and gentle suggestions from bachelor's level workers. 


\section{Boundary Crossings and Violations}

There is abundant information in the counseling literature concerning boundary issues between clinicians and clients (Borys, 1994; Borys \& Pope, 1998; Gutheil \& Gabbard, 1998; Lazarus, 1994; Nigro, 2003; Reamer, 2003). The term boundary can be defined as the edge of appropriate behavior enacted by a mental health professional to a client (Gutheil \& Gabbard). Gutheil and Brodsky (2008) added that boundaries include the physical, psychological, and social space that a client and counselor occupy in a clinical setting. Two constructs proposed by Gutheil and Gabbard help discriminate between appropriate and unquestionably inappropriate counselor-client behavior: boundary crossings and boundary violations.

The working definition of boundary crossing is as follows: "a benign variant where the ultimate effect of the deviation from the usual verbal behavior may be to advance the therapy in a constructive way that does not harm the patient" (Gutheil \& Gabbard, 1998, p. 410). Conversely, a boundary violation is defined as "when the transgression is clearly harmful to or exploitative of the patient. The harm may range from wasting time and therapeutic opportunity to inflicting severe trauma" (Gutheil \& Gabbard, p. 410). Borys (1994) asserted that the maintaining of appropriate boundaries by counselors is crucial to the welfare of the client as it provides an "arena where critical emotional issues are manifested and worked through" (p. 267). Concerning the necessity of appropriate boundaries, Pope (1994) agreed, stating: "establishing safe, reliable, and useful boundaries is one of the most fundamental responsibilities of the therapist" (p. 70). 
Borys (1994) suggested that boundaries are a multifaceted and complex phenomena, particularly with clients who may present with tremendous ambivalence about any desire for clearer boundaries. This calls to importance the necessity for clinicians to be vigilant in maintaining boundaries, since the client may not be so diligent in doing so. Pope and Keith-Spiegel (2008) described the tendency for mental health clinicians to isolate each boundary crossing and disregard the event once it is completed. In doing so, the counselor becomes naïve to the possibility that both the counselor and client's perceptions of these crossings and the impact they have may change over time. Finally, Herlihy, and Corey (1997) noted the potential far-reaching negative effects of boundary violations and argued that they may produce a ripple effect, harming clients, professionals, other clients, other professionals, and the entire counseling profession and society at large.

The mental health field historically has not reached a consensus regarding what boundaries constitute a therapeutic boundary crossing and what is an egregious boundary violation (Gabbard \& Lester, 1995; Glass, 2003; McWilliams, 2004). Lazarus (1994) has voiced criticism that many mental health professionals have established boundaries with their clients that are too rigid. He asserted that clinicians need more flexibility in the boundaries they set; otherwise, they run the risk of dehumanizing the client and hampering the therapeutic relationships. In contrast, Borys (1994) has argued that clear, structured, and consistent boundaries are crucial to client welfare, particularly because the objectivity of the clinician may be compromised when altering the boundaries. Glass (2003) advocated for a viewing of boundary crossings and violations as a continuum as opposed to a dichotomy. This spectrum of potential boundary related activities requires 
the clinician to draw upon their knowledge, professional judgment, and the personal circumstances of the client (Austin et al., 2006).

Research has shown that various factors may influence the degree to which counselors engage in boundary crossings and their attitudes about what constitutes an appropriate boundary crossing, including theoretical orientation, size of the community, sex of the counselor, and type of mental health profession (Pope \& Spiegel, 2008). However, Gutheil and Gabbard (1993) posited that healthy boundaries are not static and should not be established without taking into consideration the context in which a mental health professional is working. The authors provided an example of a counselor giving a client a ride home in a blizzard as appropriate, where it is normally not customary for an outpatient counselor to help transport a client (Gutheil \& Gabbard). Borys (1994) suggested that the impact that a clinician may have on a client when violating one's boundaries may vary depending on the presenting problem, diagnoses, and life history of the client. Clearly, much is required from a clinician in order to engage in an appropriate boundary crossing that will benefit the client.

\section{Multiple Relationships}

Boundary crossings and violations generally occur when counselors take on dual or multiple relationships. Multiple relationships exist when a clinician takes on one or more different roles with the same client. Examples of such relationships abound (e.g., counselor going into business with a client, attending the same church as a client, carrying on a social relationship with the client, and having a sexual relationship with the client). Kitchner (1988) asserted that dual or multiple relationships occur when "one 
individual is simultaneously or sequentially participating in two role categories that conflict or compete" (p. 218). A multiple relationship comes to the point where it is unethical when the relationship risks impairment of the counselor's fulfillment of expectations or responsibilities, risks exploiting the client, or risks damaging the client's emotional involvement in the professional relationship (Sonne, 1994).

Researchers have documented an alarming occurrence termed "the slippery slope phenomenon" (Gabbard, 1996; Gutheil \& Gabbard, 1998; Strasburger, Jorgenson, \& Sutherland, 1992; Williams, 1997). This occurs when a seemingly minor boundary crossing progresses from a helpful professional relationship to a harmful or exploitive one (Gutheil \& Gabbard, 1998). Gabbard has examined this progression extensively: "when no immediate disaster is detected after crossing one boundary, the therapist may begin to feel that other boundary crossings will be just as safe. The therapist then develops a false sense of security that leads to a progressive slide down the slippery slope" (p. 316). Jain and Roberts (2009) supported the validity of the slippery slope phenomenon, arguing that the most egregious violations (i.e., sexual misconduct) usually begin with minor boundary crossings. The authors also note that it is naïve and overly simplistic to believe that mental health professionals can be categorized into ethical and unethical. Furthermore, Jain and Roberts (2009) argued that the vulnerability of mental health professionals for sexual misconduct is universal.

Providing counseling within the home setting may expedite this slippery-slope phenomenon due to the informal and intimate nature of the home environment, which, as stated earlier, is perceived by some researchers (Knapp \& Slattery, 2004) to constitute a boundary crossing from the very beginning. The author noted that if the beginning phase 
of this phenomenon is characterized by more informal and friendly-oriented interactions (Gabbard, 1996), the type of interactions that the home and family environment may perpetuate.

Furthermore, a study conducted by Neukrug, Milliken, and Walden (2001) that explored ethical complaints made against credentialed counselors found the vast majority were for nonsexual dual relationships. Kitchner (1988) argued that when roles are mixed between professional and personal, the potential for ethical problems to arise significantly increases. The increased propensity for in-home counselors to engage in multiple relationships and encounter these mixed roles with clients (e.g., dinner guest, family friend, etc.) calls to importance the necessity for further scrutiny with this modality.

\section{ACA Code of Ethics and In-Home Counseling}

The ACA Code of Ethics is a highly established and ever evolving document that "provides clear parameters of behaviors to meet the changing needs of the people counselors are called to serve" (Ponton \& Duba, 2009, p. 117). The five primary purposes of this code are the following: "to clarify the nature of ethical responsibilities, to support the mission of the organization, to establish principles that inform best practice, to assist members in constructing a course of action, and to serve as the basis for processing ethical complaints and inquiries" (Ponton \& Duba, p. 117).

Given the unique settings that in-home counselors operate in, it is surprising to note that the ACA Code of Ethics (2005) is silent on the provision of in-home counseling services. Many of the ethical concepts that the code delineates are salient to in-home counseling but do not take into account the various discrepancies that exist between the 
home and outpatient settings. This absence highlights the importance of further illumination of ethical practices with in-home counseling. Complicating the matter further is the inconsistent guidance that in-home counselors sometime receive from supervisors and instructors. One in-home counselor expressed her confusion concerning a universal ethical issue of receiving goods or food from clients, noting, "therapists working in home received conflicting messages from academia and clinical trainers" (Stinchfield, 2004, p. 297). To add to the confusion, Knapp and Slattery (2004) indicated that clients generally operate from a schema or template when receiving counseling services in a clinic setting, but do not possess such a schema when counseling is provided in the home.

Section A.5.d of the ACA Code of Ethics describes "Potentially Beneficial Interactions," which are similar to boundary crossings. These interactions are described as nonprofessional interactions between a counselor and client or former client that are potentially beneficial for the client or former client. An example of a potentially beneficial nonprofessional interaction that the ACA Code of Ethics describes is attending a wedding or graduation ceremony of a client or former client. One might justify the therapeutic benefit of a counselor entering into such an endeavor. However, examples that the ACA code of ethics includes are all one-time events (e.g., attending ceremonies or hospital visits).

When a counselor is consistently working in the home environment, there may be many occasions where family members invite the counselor to participate in ongoing and repetitive events that would generally be seen as extending beyond the appropriate counselor-client boundary (e.g., sitting down for a meal with the client family). Such 
situations may also result in the ethical dilemma of receiving gifts (e.g., food from meals), which is under Standard A.10.e. One can see how in-home counseling can provide novel situations where various ethical considerations intersect.

In related fields such as research, ethical dilemmas have also been reported when conducting research within the home. More specifically, some researchers have expressed an internal struggle of identity between "the professional demands of our researcher role and the social obligations of a 'good guest"” (Yee \& Andrews, 2006, p. 398). This dilemma may manifest in the form of family members requesting advice from the researcher that is beyond the scope of researcher's role. In this particular study, the authors concluded "we found our Code (of ethics) inadequate in preparing us for the dynamic and rich diversity of family life" (Yee \& Andrews, 2006, p. 410).

Standard B.3.e of the 2005 code states, "Counselors discuss confidential information only in settings in which they can reasonably ensure client privacy." Such a disclosure may be particularly difficult in the home of a client since a counselor cannot control who may enter the household at any given moment. Neighbors, extended family members, and other friends of the family may come by announced or unannounced, over which the counselor may have little to no control (Madsen, 1999; Snyder \& McCollum, 1999).

As a final example, Standard B.1.b concerns the respect for privacy. This standard states, "counselors respect client right to privacy. Counselors solicit private information from clients only when it is beneficial to the counseling process" (ACA, 2005). What may complicate this ethical standard is that in-home counselors are already in a setting that is traditionally held as the pinnacle of privacy. As a result, the level of privacy that a 
client in an outpatient setting might expect may not necessarily be the same as a client in an in-home counseling. As it appears, the vast array of ethical dilemmas that in-home counselors face may require ethical guidelines that go beyond the scope of the 2005 ACA code.

\section{Ethics Regarding In-Home Counseling}

Several researchers have documented the existence of unique ethical situations arising in the home setting that deviate from what is considered to be traditional counseling practice (Reiter, 2000; Slattery, 2005; Snyder \& McCollum, 1999;). Slattery (2005) has noted that in general, most mental health professionals who operate in traditional outpatient settings rate the type of ethical behaviors that are common to inhome counseling to be unethical. This disparity warrants further examination of the type of situations that constitute ethical practice for in-home counselors.

Reiter (2000) posited that when working in the home environment the counselor must contend with many non-traditional therapeutic situations, such as assisting the family with washing dishes, folding laundry, and watching television programs. Reiter argued that it is incumbent upon the counselor to use these non-therapeutic situations to enhance the therapeutic relationship. Furthermore, Reiter stated that when working in the home setting, "therapists should utilize all available means to ensure a strong and meaningful relationship" (p. 32). Issues such as accepting food and drinks or having a meal with the family are commonly encountered by in-home counselors and may be a valuable opportunity to join with the family (Reiter). The author purported that clients are more open and willing to disclose information when they are involved in doing 
concrete tasks with their counselors, such as washing dishes or running errands (Reiter). Conversely, for an in-home counselor to rigidly apply therapeutic interventions to the exclusion of any non-therapeutic activity runs the risk of damaging the therapeutic relationship (Reiter).

Snyder and McCollum (1999) conducted a qualitative study of the experiences of student interns providing in-home counseling to families. By the end of the semester, the students reported a reformulation of their original views of what constituted counseling in the home setting. One student noted commented, "I feel I have 'permission' to be with the family in a way that does not resemble being in a clinic" (Snyder \& McCollum, p. 6). Resulting from this experience, the students reported a reformulation of key concepts such as counseling, boundaries, and confidentiality (Snyder \& McCollum).

Not all researchers are in agreement with the appropriateness of engaging in nontherapeutic activities. Slattery (2005) argued that mental health professionals may easily mistake paternalism, or taking care of someone, with beneficence, or doing what is therapeutically best for the client. The author argued that participating in non-therapeutic activities constitutes paternalism and is inappropriate within the parameters of the therapeutic relationship (Slattery). Furthermore, the home setting frequently places counselors into situations where they might step in and solve problems for the client instead of guiding and teaching clients to resolve problems on their own (Slattery).

Knapp and Slattery (2004) noted the tendency for counselors to take on roles that are associated with the home setting — such as parent, friend, and house guest - as opposed to mental health professional. Since roles define the relationship's boundaries, inappropriate roles may increase the risk of a boundary crossing or violation (Slattery, 
2005). Because of the unstated rules that are common to the home setting, clients may actively take on the role of host - cleaning the house beforehand, serving coffee, and attending to the counselors' needs (Slattery). When this occurs, the focus is no longer on the treatment goals, which may add to the already existing stress of the family members (Slattery). According to Snyder and McCollum (1999), the students in their study reported a common theme of familiarity with the client families, likening the atmosphere to more of a social setting than a counseling setting. Situations that promoted this social atmosphere included telephones ringing, neighbors knocking on the front door, pets crawling on counselors, and requests to hold sessions on playgrounds.

Furthermore, Snyder and McCollum (1999) found that some students working in the home were inhibited in their attempts at providing counseling due to social conventions. These students believed that it was intrusive or rude for them to interrupt the parent in their own house (Snyder \& McCollum). Indeed, researchers have noted that in the home setting, the power differential that exists between the counselor and the family has been flattened (Madsen, 1999; Mattek, Jorgenson, \& Fox, 2010; Snyder \& McCollum, 1999). Because the counselor is on the family's turf, they must be respectful of appearing as intrusive, yet still be able to facilitate the counseling session effectively. Slattery (2005) describes how counseling in an office-based setting provides clearer structure and boundaries in a variety of domains compared to the home setting. The 50-minute counseling hour, the physical confines of the one-room counseling area, and furniture exclusively used for counseling all point to the unequivocal purpose of the counseling meeting (Slattery). Because the home environment allows for greater role ambiguity, more porous boundaries, and less control by the clinician, it is crucial that the 
counseling field have a better grasp on what constitutes ethical and unethical practice with this modality.

\section{Ethical Surveys in Mental Health}

The seminal work of Pope, Tabachnick, and Keith-Speigel (1987) has served as the platform upon which many other researchers have built in creating ethical surveys. These authors conducted a survey study in 1987 that measured the ethical behaviors and attitudes of psychologists. They created the survey to include 83 ethical situations that fell under seven fundamental ethical principles e.g., nonmaleficence and confidentiality. The authors sought to measure the frequencies in which these ethical situations were encountered as well as the participants' attitudes of how ethical these situations were. A membership directory from the American Psychological Association was acquired to select participants. Demographic information was also obtained e.g., theoretical orientation, age, marital status, and gender to measure any potential relationship between those variables and responses from the survey. The authors concluded from this survey that the behaviors of psychologists were generally congruent with their beliefs, and that there existed several items that were universally seen as ethical and unethical (Pope et al.).

Pope and Gibson did a follow up study in 1993, using a modification of the survey, and sent it to National Certified Counselors. The authors added several items that they believed were more relevant for counseling and deleted items they believed were only salient for psychologists. This instrument assessed seven fundamental ethical principles, including "avoiding harm, demonstrating competence, avoiding exploitation, 
showing respect, and maintaining confidentiality, informed consent, and social equity and justice" (Gibson \& Pope, p. 331). To test reliability, an internal consistency analysis was conducted, with a Chronbach's alpha tests yielding .88 for the yes or no scale, and .97 for the confidence level scale (Gibson \& Pope, 1993). Recently revised by Milliken and Neukrug (2009), the latest survey was modified after reviewing the ACA Ethical Code, examining research on ethical complaints and violations made against counseling professionals and a review of hot topics discussed on professional listservs. This survey has also been adapted and administered to social workers; however, the primary focus is that of sexual attraction with clients (Bernsen, Tabachnick, \& Pope, 1994). A study of 453 social workers also compared their results to that of psychologists in the original study, and the authors found significant differences between the two groups in several domains (Bernsen, Tabachnick, \& Pope, 1994).

Other surveys used include the Exploitation Index (EI; Epstein \& Simon, 1990). This survey consists of 32 questions and is "designed as a self-administered educational inventory intended to assist psychotherapists in evaluating their potential for violating boundaries in the course of treating patients" (Epstein et al., 1992, p. 151). The Exploitation Index has seven subscales, which include, "generalized boundary violations, eroticism, dependency, exhibitionism, power seeking, professional and ethical behaviors, and enabling" (Swiggart et al., 2008, p. 179). This index focuses on frequencies of behaviors of clinicians. The subscales are measured along a 4-point Likert scale, with the response categories of never, rarely, sometimes, and often (Epstein \& Simon, 1990).

Epstein et al. (1992) conducted a follow-up survey to evaluate the usefulness of this instrument. They surveyed 532 psychiatrists and psychoanalysts and found that 
"forty-three percent of the respondents indicated that at least one item alerted them to behavior they thought could have been counterproductive to treatment. Twenty-nine percent found that they were stimulated to make specific changes in future treatment practice" (Epstein et al., p. 150). Item reliability of the El was determined by calculating Cronbach's Alpha, which was .81 , indicating a moderately high coherence within the item set (Epstein et al., p. 150). Additionally, factor analysis suggests that various subcategories of exploitation may be discerned using the EI as a self-assessment questionnaire.

Borys completed her dissertation in 1988 , studying the dual relationships of mental health professionals. She created her own survey, the Therapeutic Practices Survey, which contained 20 situations under 3 subscales (Incidental Activities, Financial/Social Activities, and Multiple Roles). The author conducted a pilot study of 20 psychologists to seek validity. Borys administered her survey to professionals in three mental health disciplines: psychiatry, psychology, and social work. The author selected participants through a directory of national associations. All participants were mailed the same survey, but half were asked about the ethicality of the situations, while the other half were asked about the frequencies in which they engaged in these situations. Similar to Pope's study, there was no consideration for in-home counseling.

\section{Ethical Surveys for In-Home Counseling}

While there is a noticeable paucity of research regarding the ethical dimensions of in-home counselors, there exist a notable few. Roberts (2006) attempted to explore the differences between master's level in-home counselors and master's level office-based 
counselors $(\mathrm{N}=97)$ in Pennsylvania and Ohio regarding their ethical concerns.

Additionally, the author studied the effect that ethics courses, gender, training level, race, licensure status, and theoretical orientation had on the ethical concerns between the two groups. Furthermore, Roberts asked subjects to report the ethical violations that they believed their peers experienced.

The most significant result of this study was that in-home counselors reported a significantly higher frequency of ethical violations that they perceived peers to participate in, especially regarding issues of confidentiality and role confusion (Roberts, 2006). The author believed this confirmed prior research stating that in-home counselors are at a higher risk for an incompatibility between their roles, a divergence of obligations of their roles, and difference of power and prestige between counselor and client. However, clearly more research is needed in this understudied population.

Another study, conducted by Worth (2004), sought to examine the attitudes, experiences, and practice concerns of in-home counselors $(\mathrm{N}=174)$. Included in these experiences were ethical dilemmas that were encountered by in-home clinicians. The population sampled included members of the American Association for Marriage and Family Therapy, (AAMF), the American Counseling Association (ACA), and the National Association of Social Workers (NASW). Of the respondents, $43 \%$ provided ethical dilemmas they had encountered in the home (Worth). The most prevalent of these themes were boundary-related issues $(N=22)$, followed by confidentiality $(N=18)$; also noted were legal issues surrounding a non-client $(\mathrm{N}=7)$, legal issues surrounding the client $(N=5)$, distractions in the home $(N=4)$, and client sexual attraction to the counselor $(\mathrm{N}=3)$. 
While these themes are illuminating, they are qualitative, thus lacking generalizability. Additionally, the study captured only those in-home counselors who possessed a master's degree and who were members of a national association. As stated earlier, Medicaid allows for bachelor's level clinicians to provide in-home counseling (DMAS, 2008). The limited training and education that these professionals may possess lends credence to the need for greater exploration of attitudes of in-home counselors regarding ethical situations. 


\section{CHAPTER THREE}

\section{METHODOLOGY}

\section{Purpose}

The design for this study was quantitative and had four primary purposes. The first purpose was to explore the attitudes of in-home counselors and outpatient counselors regarding ethical situations that are typically encountered by in-home counselors. The second purpose was to explore any differences in responses by counseling modality (inhome, outpatient). The third purpose was to explore the degree that the independent variables of modality, gender of counselor, discipline (social work, counseling, psychology, etc.), education, employment status (part-time or full-time), years of experience as an in-home counselor, years of experience as a mental health professional, license or certification, and percentage of work providing in-home counseling compared to case management predicted in-home and outpatient counselors' attitudes about ethical situations typically encountered by in-home counselors. The fourth purpose was to explore the degree that the independent variables predicted in-home counselors' attitudes about ethical situations encountered by in-home counselors. A survey instrument and personal information form was used to gather information from participants. I developed the instruments that were utilized in this study. Ten of 21 items in the survey instrument were adapted from a survey created by Roberts (2006). The survey instrument was reviewed by professionals and leaders in the field as part of an instrument validation process. In addition, the instrument was administered to a small group of in-home and 
outpatient counselors as part of a pilot study and they were asked to provide input on the contents of the instrument before the instrument was finalized.

\section{Variables}

The dependent variables in this study were the self-reported attitudes of in-home and outpatient counselors regarding ethical situations typically encountered by in-home counselors. The independent variables in this study included counseling modality (primarily in-home, primarily outpatient) gender of counselor, discipline (social work, counseling, education, psychology, human services, school psychology, clinical psychology, other), degree (high school diploma, associate's degree, bachelor's degree, educational specialist degree, doctoral degree, other), employment status (part-time, fulltime), years of experience as an in-home counselor, years of experience as a mental health professional, license and certifications (Licensed Professional Counselor, Licensed Clinical Social Worker, National Certified Counselor, Qualified Mental Health Professional, Certified Substance Abuse Counselor, Licensed Counseling Psychologist, Licensed Clinical Psychologist, Licensed Marriage and Family Therapist, other), and percentage of work providing in-home counseling compared to case management.

\section{Research Design}

The study used a quantitative, non-experimental research design. The research packet included an informed consent form, a personal information form, as well as a survey instrument. Ethical situations that are salient to the in-home counseling field were presented in the survey and participants were asked to rate the degree to which they 
believed the situations were ethical or not ethical. Additionally, the participants were pooled from a cross-sectional convenience sample of various counseling agencies in the state of Virginia. This type of design was ideal for collecting data of a given population at one point in time and measuring differences among groups within the population (Weirsma \& Jurs, 2009).

\section{Research Questions}

A survey instrument measured the attitudes of in-home and outpatient counselors regarding ethical situations typically encountered by in-home counselors. This survey was developed through an extensive review of the literature to identify ethical concerns that are most salient to the in-home counseling modality. Additionally, several items were adapted from a dissertation created by Roberts (2006) who examined the differences between in-home counselors and office based counselors regarding the frequency of ethical violations. Professionals and leaders in the field of in-home counseling reviewed the survey to verify the validity and the credibility of the instrument. The following research questions were addressed in the study:

1. What is the difference, if any, between in-home and outpatient counselors' attitudes about ethical situations typically encountered by in-home counselors?

2. To what degree do the following variables predict in-home and outpatient counselors' attitudes about ethical situations typically encountered by in-home counselors

- Gender

- Modality 
- Mental health field

- Education

- Employment status

- Years of experience as a mental health professional

- Licenses and certifications held

- Percentage of work providing in-home counseling compared to case management.

3. To what degree do the following variables predict in-home counselors' attitudes about ethical situations typically encountered by in-home counselors

- Gender

- Mental health field

- Education

- Employment status

- Years of experience as an in-home counselor

- Years of experience as a mental health professional

- Licenses and certifications held

- Percentage of work providing in-home counseling compared to case management.

\section{Participants}

Participants were in-home and outpatient counselors who currently work at licensed agencies in the state of Virginia. I contacted directors of various agencies in order to gather potential recruits. The agencies were selected from a directory of those 
licensed by the Department of Behavioral Health and Developmental Services (DBHDS). I asked each agency director to provide me with the email addresses of his or her counselors so that I could contact them directly, asking them to participate in the study. If the agency director was not willing to provide these email addresses, the director was asked to forward an email message to his or her employees from me requesting participation in the study, and inform me regarding how many counselors to whom the email message was sent. Utilizing the recommendations of Cohen (1992) as a guideline, assuming medium effect size of a $0.15, \alpha=.05$, a minimum of 107 participants were determined to be needed for this study.

\section{Study Context/Setting}

This study took place online utilizing Survey Monkey, an online survey builder. Survey Monkey contained an introduction, informed consent to participate page, and the survey. The survey included the attitudes regarding ethical situations typically encountered by in-home counselors questionnaire and personal information form. Participants were able to complete the survey at their convenience and return it no later than a specified date.

\section{Instrumentation}

According to Babbie (1990) a survey design is the recommended approach when the purpose is exploratory in nature; seeking to discover the distributions of traits and behaviors of an understudied population as well as making explanatory assertions. As a result, participants in this study utilized a self-reported web-based Internet survey. The 
survey instrument used in this study contained three sections in addition to an informed consent form that also displayed the approval by the Institutional Review Board (IRB). The first section of the study examined the attitudes of in-home and outpatient counselors regarding ethical situations typically encountered by in-home counselors. The second section consisted of a personal information form that collected demographic information. The final section consisted of an open-ended question concerning other in-home counseling ethical issues the participants may have observed or encountered.

\section{Survey instrument.}

The first section of the survey included 21 ethical situations that in-home counselors may encounter while in the field. Participants were asked to rate these 21 situations regarding the degree to which they believed them to be ethical or not ethical. The responses were rated on a 5-point Likert scale $(1=$ Never ethical, $2=$ Ethical under rare conditions, $3=$ Ethical under some conditions, $4=$ Ethical under most conditions, and $5=$ Always ethical). For the second section, participants were asked to provide personal information. On the final section of the instrument, participants were asked to provide any additional ethical issues that they may have observed or encountered while providing in-home counseling.

\section{Item generation and content validation.}

Ten of the 21 survey items generated were adapted from a dissertation by Roberts (2006) who explored the differences between in-home and office-based counselors regarding ethical violations. Roberts' (2006) scale asked participants to rate the 
frequencies of ethical behaviors they believed other therapists engaged in within a year. His survey was modified from several surveys (Borys \& Pope, 1989; Epstein \& Simon, 1990; Pomerantz, et al., 1998) with items measuring four defined spectrums (confidentiality, role confusion, client diffusion and unintentional witnessing). Roberts (2006) sent his survey to six in-home professionals in the field for further validation of the content validity.

Of the remaining 10 items on the survey, two were adapted from a survey developed by Milliken and Neukrug (2009), which is an updated form of Gibson and Pope's (1993) survey administered to National Certified Counselors. One item was modified from the original item "Consoling your client by touching him or her (e.g., placing your hand on his or her shoulder)" (Milliken \& Neukrug, 2009) and changed to "consoling a distraught client by cradling or holding him or her." This item was changed because of the increased potential for boundaries to be blurred when working in the homes of clients. In-home counselors may begin to take on roles that are similar to those of family members, especially considering the environment in which they are working with clients (e.g., on couches, floors, beds, etc.). Additionally, Knapp and Slattery (2004) noted the tendency for families to treat clinicians as friends or guests, as opposed to their assigned counselor. When clients view the in-home counselor in a nonprofessional role, they may potentially hasten the steps toward the slippery slope that might result in an ethical violation.

The remaining items were developed from a thorough examination of the peerreviewed literature that illuminated issues most salient to in-home counseling. These items included issues of safety, witnessing violence, distractions, and participating in 
non-therapeutic family activities (Adams \& Maynard, 2000; Christensen, 1995; Cortes, 2004; Thomas et al., 1999; Wasik \& Bryant, 2001). After receiving feedback from expert reviewers of the instrument, feedback from counselors who participate in the pilot study, and discussions with committee members, a final list of items was created. This section of the form took approximately 5-7 minutes to complete.

Participants completed a personal information form that included counseling modality of primary use (in-home, outpatient) gender, discipline (social work, counseling, psychology, etc.), education, employment status (part-time or full-time), years of experience as an in-home counselor, years of experience as a mental health professional, licenses or certifications held (e.g., LPC, NCC, QMHP, etc.), and percentage of work providing in-home counseling compared to case management. This personal information was used to compare differences within these categorical variables to the frequencies of the subscales provided by the survey instrument. This section of the form took approximately 3 minutes to complete.

For establishing validity, this initial list of items was sent to an expert panel of inhome professionals and experts in the counseling field. The expert panel included directors, clinicians, and researchers. These experts were asked if they believed the survey instrument adequately addressed the ethical issues that are of concern in in-home counseling. Additionally, experts were asked to provide any items they believed should be included in the instrument and also comment on any of the items that may be confusing or poorly worded. Resulting from this feedback and discussion with committee members, several items were modified, and one item was added to the instrument. 
Some examples of changes made as a result of the expert review are provided. One of the expert reviewers, an executive director of an in-home counseling agency, suggested that the wording of item 8 in Section 1 be changed from "strongly encouraging a client or a client's family member to apply for needed services" to "telling a client or a client's family member to apply for needed services." This expert argued for the need to use stronger wording because of the case management component that was imbedded within in-home counseling, where ensuring proper linkage of services to clients was a normal function. Another expert reviewer, an in-home counseling supervisor, suggested the inclusion of a situation involving the provision of counseling to a minor when his or her parents or guardians are not home. This expert reviewer noted both the high frequency of encountering this situation as well as the significant anxiety that it produced for her. The item was subsequently added to the instrument. As a final example, one expert reviewer commented on the personal information form, noting the education of some in-home counselors did not include a GED, but only a high school diploma. As a result, GED was added to item 2 in Section 2.

Following the expert review, a pilot study was conducted with 20 participants. A preliminary exploratory factor analysis was performed in order to identify emerging constructs and to determine if scale items were appropriate for inclusion in the instrument. Additionally, a preliminary reliability analysis was computed across the identified constructs. Results from the pilot study were not included in the final analysis.

\section{Procedures}


In accordance with Federal Codes (Code of Federal Regulations Title 45 Part 46, [45CFR46] and the state of Virginia regulations (Virginia Code 32.1-162.16 et seq.:), the Human Subjects Review Board at Old Dominion University has reviewed and approved the proposed procedures and instrumentation. Directors and supervisors of counseling agencies were personally contacted and I asked to be provided a list of email addresses of counselors who work at the agency. If the director or supervisor did not feel comfortable providing the list, I provided the director or supervisor with the link to the survey and asked him or her to contact employees, give them the link, and ask them to complete the survey. I asked to be informed regarding the number of counselors to whom each director or supervisor sent surveys

For the email addresses obtained, participants were contacted and sent a letter, notifying them of the survey opportunity. Included in the letter was an informed consent form that fully delineated the risks and benefits of participating in the study. 


\section{CHAPTER FOUR}

\section{RESULTS}

This study explored the attitudes of in-home and outpatient counselors in the Commonwealth of Virginia regarding ethical situations typically encountered by in-home counselors. This chapter reports the results of this survey study. First, a summary of the demographic information collected is presented. Second, a description of the data screening process is presented. Third, descriptive data for the outcome variable are presented. Fourth, the results of the multivariate statistical analyses conducted are presented. Fifth, a summary of the results from the open-ended comments in Section III of the survey instrument is presented. Finally, a summary of the results is presented.

\section{Demographic Information}

In total, the directors of 96 agencies licensed by the Department of Behavioral Health and Developmental Services (DBHDS) were asked by either phone or email to distribute the survey in this study to counselors employed in their agency. Of the 96 agencies contacted, 21 directors agreed to forward the survey to their counselors. The directors who were contacted were also asked to provide the number of counselors who worked at their agency. Because not every director provided the number of counselors 
working at the agency, and the possibility that the survey was forwarded to other agencies, the response rate is only an approximation. From the information provided, 821 counselors were asked to complete the survey. Of the 821 counselors to whom the survey was sent, 120 responded $(\mathrm{N}=120)$, equating to a response rate of $14.8 \%$.

Upon completion of data screening, the 108 participants whose data was valid were found to possess the following demographic characteristics; $71 \%$ were female, $66 \%$ identified as in-home counselors, and $83 \%$ reported working full-time. Of the 107 participants who responded to the question about education level, the majority, $61 \%$, reported having a master's degree, while $18 \%$ reported having a bachelor's degree. Furthermore, $9 \%$ of participants reported possessing a doctoral degree, $7 \%$ reported having an educational specialist degree, and 5\% reported having an associate's degree or less.

Regarding the mental health field of the participants, $38 \%$ reported having a counseling background and $31 \%$ reported social work. Furthermore, $10 \%$ of the participants reported coming from the mental health field of psychology, while clinical psychology, education, and human services were each reported by $6 \%$ of participants, respectively. No response was given by $3 \%$ of the participants.

Pertaining to licenses and certifications held, descriptive data showed that the majority of the respondents, $50 \%$, reported that they possessed the certification of a Qualified Mental Health Professional (QMHP). The second largest credential reported was Licensed Clinical Social Worker (LCSW) at 22\%, and close behind was Professional Counselor at $20 \%$. The remainder of the participants identified as Other Mental Health 
Provider at 4\%. Table 1 displays participant education, licensure, and certification characteristics.

Table 1

Degrees Earned and Licenses and Certifications Held

Degree Earned

Associate's Degree or Less

5

5

Bachelor's Degree

19

18

Master's Degree

66

61

Educational Specialist Degree

7

7

Doctoral Degree

10

Licenses and Certifications Held

Qualified Mental Health

54

Professional

Licensed Clinical Social Worker

24

22

Professional Counselor

22

20

Other Mental Health Provider

4

Mental Health Field

Counseling

Social Work

Psychology

11 
Education

Human Services

Clinical Psychology
6

6

6
6

6

6

The percentage of work reported providing counseling compared to case management services can be found in Table 2 . Both the majority of in-home $68 \%$ and outpatient $60 \%$ counselors reported their distribution of work as $75 \%$ providing counseling and $25 \%$ providing case management services. None of the participants reported providing $0 \%$ counseling and $100 \%$ case management.

Table 2

Percentage of Counseling Compared to Case Management

\begin{tabular}{lcc} 
& Frequency & Percent \\
\hline $100 \%$ Counseling, 0\% Case Management & 7 & 7 \\
$75 \%$ Counseling, 25\% Case Management & 71 & 66 \\
$50 \%$ Counseling, 50\% Case Management & 16 & 15 \\
$25 \%$ Counseling, 75\% Case Management & 14 & 13 \\
\hline
\end{tabular}

\section{Data Screening}

A total of 120 participants $(\mathrm{N}=120)$ responded to the survey. Data screening was first employed, which resulted in 11 cases being deleted from the study due to missing 
data or incomplete responses. Two other missing values for the study's dependent variable (responses to the 21 ethical situations) were recoded into the mean value of the composite score of each item.

The independent variables, Number of Years Providing In-Home Counseling and Number of Years Working as a Mental Health Professional, had 15\% and 11\% missing values, respectively. It was also determined that these two variables were related to one another and as a result, number of years providing in-home counseling was omitted from the study. Because the missing values of years working as a mental health professional were between $10 \%$ and $15 \%$, the missing values were recoded to the mean value for the variable. Data were then screened to ensure that the assumptions of multiple regression were fulfilled. Data were first screened for univariate outliers. Two extreme values from the dependent variable were identified and both values were recoded to the maximum non-extreme value. Univariate outliers were also examined for each respective modality (in-home and outpatient). No univariate outliers were identified. Data were screened for univariate normality using Levene's test of homogeneity of variances. Levene's test was not significant for all variables at $p=.05$. The independent variable Employment Status had a split of $83 \%$ for full-time and $17 \%$ for part-time and because of the severe split between the levels of this dichotomous variable, it was omitted from the study.

Data were then screened for multivariate outliers. Mahalanobis' distance was computed. None of the cases exceeded the critical chi-square value of 27.89. However, upon calculating Mahalanobis Distance for each respective modality (in-home and outpatient), one in-home case was identified as an outlier. Consequently, the case was deleted. 
Next, multivariate normality and linearity were examined by way of scatterplot matrix. The scatterplot matrix revealed shapes that are close to elliptical. Additionally, multivariate homoscedasticity was examined by way of residual plots. The residual plots were also close to elliptical, indicating that the assumption of multivariate normality and linearity was not violated.

\section{Descriptive Data}

Outcome data consisted of the participants' responses regarding ethical situations on a Likert scale from 1 to $5(1=$ Never ethical, $2=$ Ethical under rare conditions, $3=$ Ethical under some conditions, $4=$ Ethical under most conditions, and $5=$ Always ethical). Table 3 displays the means and standard deviations of each item, beginning from lowest mean to highest. All of the 21 items had the maximum range of 4 , meaning that for every item there was a respondent who scored the item 1 (Never Ethical) and another respondent who scored the same item 5 (Always Ethical). Item number 8 'telling a client or a client's family member to apply for needed services (e.g., applying for food stamps, applying for a psychiatric or medical evaluation, etc.)"-was ranked the highest $(M=4.04)$ and thus was seen as the most ethical $(4=$ Ethical Under Most Conditions). Item number 20-“Continuing to provide counseling to a client after it becomes apparent that the client has a serious problem (e.g., schizophrenia, major depression, etc.) for which you have not been trained to provide services or treatment"was ranked the lowest $(M=1.60 ; 1=$ Never Ethical, $2=$ Ethical Under Rare Conditions). Item number 17- "Not being a member of a professional association in counseling or related field"- - had the largest standard deviation $(S D=1.51)$ and thus the largest 
disagreement among respondents. Item number 3-“Visiting, calling, or sending email messages to a client or a client's family member after termination"- - had the lowest standard deviation $(S D=.83)$ and thus the most agreement $(M=1.80)$. Individual item means and standard deviations for the entire participant sample (combined modalities), in-home sample, and outpatient sample are presented in Table 3. Items are listed in rank order from 1 (Never Ethical) to 5 (Always Ethical).

Table 3

Attitudes of Counselors Regarding Ethical Situations
Combined

Modalitie In-Home Outpatient $\mathrm{s}$

Scout cookies, etc.)

16. Providing counseling to the client while someone not in the family (e.g., neighbor, houseguest, relative) is within hearing distance

3. Visiting, calling, or sending email messages to a client or a client's family member after termination

5. Accepting an invitation from a client to attend a personal event (e.g. Christmas dinner, hospital visitation for a family member who is ill, etc.) 
4. Talking to your friends or your family members who

$\begin{array}{ccc}1.90 & 1.82 & 2.05 \\ (1.12) & (1.00) & (1.31)\end{array}$

of a client or a client's family members without

revealing identifying information

10. Providing individual counseling to a relative, friend,

or significant other of a current client or of a client's

family member.

14. Consoling a distraught client by cradling or holding

him or her.

(.91)

2. Giving a client or client's immediate family member a ride in your car to do an errand that is not related to the

client's therapeutic goals (e.g., to the bank or grocery store)

6. Disclosing details of a personal nature (e.g., your own health problems, future employment concerns, family

history issues, etc.) to a client or a client's family member

15. Eating a meal with a client or a client's family member when an invitation is offered

21. Providing counseling to a minor when his or her

parents or guardians are not at home

18. Providing counseling to a client in a public location where privacy cannot be guaranteed (e.g., coffee shop, park, or library)

11. Answering questions regarding non-therapeutic think is the best place to get a car loan?" "Could you tell me how to set up my DVD player?")

9. Counseling a client in the client's bedroom to minimize distractions during the counseling session

19. Providing advice that is requested by a client about how to help an individual whom the client knows who has a mental health problem (e.g., "I have a friend who I think is Bipolar, how can I help her?")

17. Not being a member of a professional association in counseling or related field 
12. Observing or acquiring direct evidence that a client or his or her family members are involved in criminal activity (e.g., selling drugs in the house) and reporting the criminal activities to law enforcement authorities

1. Providing a snack item for the client (e.g., a candy bar, soda, or pack of gum) for which the counselor is not reimbursed

8. Telling a client or a client's family member to apply for needed services (e.g., applying for food stamps, applying for a psychiatric or medical evaluation, etc.)

In examining the means in relation to the 5-point Likert scales, it is interesting to note that 17 out of the 21 items had a value less than $3(3=$ Ethical Under Some Conditions), indicating that the vast majority of items were perceived to be unethical. Of the remaining 4 items, three were slightly above the value three. Item number $1-$ "Providing a snack item for a client (e.g., a candy bar, soda, or a pack of gum) for which the counselor is not reimbursed)" - had a mean score of $M=3.35$, which is a little more than "Ethical Under Some Conditions," while item number 17-"Not being a member of a professional association in counseling or a related field," had a mean score of $M=3.18$, and is also slightly more than "Ethical Under Some Conditions." Item 12-“Observing or acquiring direct evidence that a client or his or her family members are involved in criminal activity (e.g., selling drugs in the house) and reporting the criminal activities to law enforcement authorities," had a mean score of $M=3.26$, and is similarly seen as more than "Ethical Under Some Conditions." Only item number 8-“telling a client or a client's family member to apply for needed services (e.g., applying for food stamps, applying for a psychiatric or medical evaluation, etc.)"$(M=4.04)$.

Descriptive statistics were also computed for each respective modality (In-home and Outpatient). These results are presented in Table 3. For the modality of in-home, item 
number 8-“telling a client or a client's family member to apply for needed services (e.g., applying for food stamps, applying for a psychiatric or medical evaluation, etc.)"'had the highest mean $(M=4.10)$, which was slightly higher compared to the overall mean $(M=4.04)$. Thus, this situation was seen as the most ethical $(4=$ Ethical Under Most Conditions). Item number 20-“Continuing to provide counseling to a client after it becomes apparent that the client has a serious problem (e.g., schizophrenia, major depression) for which you have not been trained to provide services or treatment"-still had the lowest mean $(M=1.64)$ compared to $(M=1.60)$ for the overall mean $(1=$ Never Ethical, 2 = Ethical Under Rare Conditions).

For the modality of outpatient, item number 8-“telling a client or a client's family member to apply for needed services (e.g., applying for food stamps, applying for a psychiatric or medical evaluation, etc.)"- - had the highest mean although slightly lower $(M=3.89)$ compared to the overall mean $(M=4.04)$, and thus was seen as the most ethical ( 4 = Ethical Under Most Conditions). Item number 20-“Continuing to provide counseling to a client after it becomes apparent that the client has a serious problem (e.g. schizophrenia, major depression) for which you have not been trained to provide services or treatment" — still had the lowest mean, but at $(M=1.51)$ compared to $(M=1.60)$ for the overall mean $(1=$ Never Ethical, $2=$ Ethical Under Rare Conditions $)$.

\section{Research Question 1}

Research question 1 asked, "What is the difference, if any, between in-home and outpatient counselors' attitudes about ethical situations typically encountered by in-home counselors?" 
The null hypothesis for research question 1 stated, "There is no significant difference between in-home and outpatient counselors' attitudes about ethical situations typically encountered by in-home counselors."

To answer the first research question, an independent sample $t$-test was conducted to determine if there was a difference between in-home and outpatient counselors' attitudes about ethical situations typically encountered by in-home counselors. Results revealed that there was not a significant difference in the scores for in-home $(M=2.33$, $S D=.42)$ and outpatient $(M=2.22, S D=.43)$ responses; $t(106)=1.231, p=.221$. The results of this analysis failed to reject the null hypothesis for this research question.

Additionally, independent $\mathrm{t}$-tests were conducted for of each of the 21 ethical situations on the survey to determine if there was a difference between in-home and outpatient counselors' responses to each item. Only the item "Observing or acquiring direct evidence that a client or his or her family members are involved in criminal activity (e.g., selling drugs in the house) and reporting the criminal activities to law enforcement authorities" was found to be statistically significant with regard to the scores for in-home $(M=3.48, S D=1.34)$ and outpatient $(M=2.84, S D=1.42)$ responses; $t(106)=2.309, p$ $=.023$. These results suggest that in-home counselors believed this item to be more ethical than outpatient counselors.

\section{Research Question 2}

Research question 2 asked, "To what degree do the following variables predict inhome and outpatient counselors' attitudes about ethical situations typically encountered by in-home counselors 
- Gender

- Modality

- Mental health field

- Degree

- Employment status

- Years of experience as an in-home counselor

- Years of experience as a mental health professional

- Licenses and certifications held

- Percentage of work providing counseling compared to case management."

The null hypothesis for this question stated that the above variables would not significantly predict in-home and outpatient counselors' attitudes about ethical situations typically encountered by in-home counselors.

Standard multiple regression was conducted to determine whether the variables predicted in-home and outpatient counselors' attitudes about ethical situations typically encountered by in-home counselors, as measured by participants' overall scores on attitudes of ethical situations questionnaire. Four of the independent variables were dummy coded because they had more than two levels (degree, mental health field, licenses and certifications held, and counseling compared to case management). Multicollinearity among predictor variables was examined by viewing tolerance levels and Variance Inflation Factors (VIF) for each variable. In this model, three levels of three variables were excluded due to low tolerance levels: counseling $75 \%$ and case management $25 \%$, and master's degree. 
The standard multiple regression analysis indicated that the overall model did not significantly predict attitudes of counselors regarding ethical situations encountered by in-home counselors, $F(12,90)=.622, p=.818$. A summary of the regression coefficients revealed that only one independent variable significantly contributed to the prediction of this model: $25 \%$ counseling, $75 \%$ case management $(t=1.987, p=0.05)$. Regression coefficients are presented in Table 4.

Table 4

Summary of Multiple Linear Regression Predicting Counselors' Attitudes About Ethical Situations Typically Encountered by In-Home Counselors

\begin{tabular}{|c|c|c|c|c|c|}
\hline Coefficients & $B$ & $S E B$ & $\beta$ & $t$ & Sig. \\
\hline Gender & .053 & .100 & .058 & .526 & .600 \\
\hline Degree & .011 & .085 & .023 & .127 & .899 \\
\hline Modality & -.039 & .096 & -.044 & -.403 & .688 \\
\hline $\begin{array}{l}100 \% \text { Counseling, } 0 \% \\
\text { Case Management }\end{array}$ & .176 & .212 & .106 & .828 & .410 \\
\hline $\begin{array}{l}\text { Years as a Mental } \\
\text { Health Professional }\end{array}$ & -.006 & .006 & -.119 & -1.050 & .297 \\
\hline $\begin{array}{l}25 \% \text { Counseling, } \\
75 \% \text { Case Management }\end{array}$ & -.134 & .067 & -.255 & -1.987 & .05 \\
\hline $\begin{array}{l}50 \% \text { Counseling, } \\
50 \% \text { Case Management }\end{array}$ & .059 & .131 & .050 & .452 & .652 \\
\hline $\begin{array}{l}\text { Associate's Degree or } \\
\text { less }\end{array}$ & .021 & .286 & .011 & .074 & .941 \\
\hline Bachelor's Degree & .093 & .164 & .086 & .568 & .572 \\
\hline $\begin{array}{l}\text { Educational Specialist } \\
\text { Degree }\end{array}$ & -.019 & .201 & -.011 & -.095 & .924 \\
\hline LCSW & .052 & .128 & .052 & .403 & .688 \\
\hline
\end{tabular}


Other Mental Health

Provider

Professional Counselor
.031 $-.012$
.081

.455
.050

.376

.708

$-.013$

The results of the regression model failed to reject the null hypothesis; there is no statistically significant finding in the overall model of the demographic variables predicting in-home and outpatient counselors' attitudes about ethical situations typically encountered by in-home counselors. However, as shown in Table 3, one independent variable, $25 \%$ counseling and $75 \%$ case management, significantly contributed to the prediction of this model.

\section{Research Question 3}

The third research question asked, "To what degree do the following variables predict inhome counselors' attitudes about ethical situations typically encountered by in-home counselors

- Gender

- Mental health field

- Degree

- Employment status

- Years of experience as a mental health professional

- Licenses and certifications held

- Percentage of work providing counseling compared to case management." 
The null hypothesis for this question stated that the above variables would not significantly predict in-home counselors' attitudes about ethical situations typically encountered by in-home counselors.

This question was analyzed using multiple regression to determine whether the variables significantly predict in-home counselors' $(n=66)$ attitudes about ethical situations typically encountered by in-home counselors, as measured by participants' overall scores on the attitudes of ethical situations questionnaire. Multicollinearity among predictor variables was examined by viewing tolerance levels and Variance Inflation Factors (VIF) for each variable. In this model, three levels of three variables were excluded due to low tolerance levels: counseling $75 \%$ and case management $25 \%$, and bachelor's degree.

The standard multiple regression analysis indicated that the overall model did not significantly predict attitudes of counselors regarding ethical situations encountered by in-home counselors, $F(11,54)=.323, p=.977$. A summary of regression coefficients presented in Table 5 indicated that one of the variables significantly contributed to the model.

Table 5

Summary of Multiple Linear Regression Predicting In-Home Counselors' Attitudes About Ethical Situations Typically Encountered by In-Home Counselors

\begin{tabular}{|lccccc|}
\hline Coefficients & $B$ & $S E B$ & $\beta$ & $t$ & Sig. \\
\hline Gender & -.060 & .146 & -.063 & -.410 & .683 \\
Degree & -.016 & .101 & -.036 & -.163 & .871 \\
Other Mental Health Provider & .004 & .112 & .006 & .035 & .973
\end{tabular}




\begin{tabular}{|lccccc|}
$\begin{array}{l}25 \% \text { Counseling, 75\% Case } \\
\text { Management }\end{array}$ & -.075 & .200 & -.131 & -.750 & .457 \\
$\begin{array}{l}\text { Years as a Mental Health } \\
\text { Professional }\end{array}$ & .008 & .009 & .133 & .811 & .421 \\
$\begin{array}{l}\text { 100\% Counseling, } \\
0 \% \text { Case Management }\end{array}$ & -.192 & .248 & -.123 & -.773 & .443 \\
$\begin{array}{l}50 \% \text { Counseling, } \\
50 \% \text { Case Management }\end{array}$ & -.062 & .181 & -.054 & -.342 & .734 \\
Associate's Degree or less & .101 & .358 & .051 & .282 & .779 \\
Master's Degree & -.070 & .138 & -.082 & -.505 & .616 \\
Educational Specialist Degree & -.418 & .368 & -.173 & -1.135 & .261 \\
LCSW & -.098 & .202 & -.088 & -.484 & .631 \\
Other Mental Health Provider & .031 & .081 & .050 & .376 & .708 \\
Professional Counselor & .153 & .492 & .152 & .312 & .756 \\
Qualified Mental Health Provider & -091 & .408 & -.106 & -.224 & .824 \\
\hline
\end{tabular}

The results of the regression model failed to reject the null hypothesis; there is no statistically significant finding in the overall model of the demographic variables predicting in-home counselors' attitudes about ethical situations typically encountered by in-home counselors.

\section{Section III: Comments}

Section III of the survey instrument asked participants to comment on their own personal experiences regarding ethical issues they had observed while providing in-home counseling. Of the 108 complete responses, 41 participants provided comments in Section III. Several participants stated that they had encountered situations similar to the 
items listed on the survey. These items included the following: observing illegal activities performed by clients, family visitors arriving unexpectedly, having clients contact their counselor after termination, having a meal with a client, counselors being invited to birthday parties and events, counselors not being competent to handle certain client cases, working in a client's home despite feeling unsafe, and counselors disclosing too much personal information to clients.

Ethical situations that were reported and not mentioned in the survey included the following: inadequate supervision, inadequate risk assessment of families, unqualified supervisors, parents intoxicated, clients asking to borrow money, clients providing gifts, clients considering counselors as another member of the family, small community resulting in a natural ongoing relationship between client and counselor, counselors with only bachelor's degree and thus being unqualified, donating items to a client in need, and billing issues when two counselors are working in the home.

\section{Summary of Results}

This study explored the attitudes of in-home and outpatient counselors in the commonwealth of Virginia regarding ethical situations typically encountered by in-home counselors. More specifically, this study examined any differences between in-home and outpatient counselors' attitudes about ethical situations typically encountered by in-home counselors. Additionally, nine demographic variables were examined to discern if they predicted in-home and outpatient counselors' attitudes about ethical situations typically encountered by in-home counselors. The first section of the survey included 21 ethical situations that in-home counselors may encounter while in the field. The responses were 
rated on a 5-point Likert scale, $(1=$ Never ethical, $2=$ Ethical under rare conditions, $3=$ Ethical under some conditions, $4=$ Ethical under most conditions, and $5=$ Always ethical). For the second section, participants were asked to provide personal information. On the final section of the instrument, participants were asked to provide any additional ethical issues that they may have observed or encountered while providing in-home counseling.

Results showed that there was not a significant difference between in-home and outpatient counselors' attitudes about ethical situations typically encountered by in-home counselors. Furthermore, of the independent variables (gender, modality, mental health field, education, employment status, years of experience of a mental health professional, years of experience as an in-home counselor, licenses and certifications held, and percentage of work providing in-home counseling compared to case management), only one variable, $25 \%$ counseling, $75 \%$ case management predicted in-home and outpatient counselors' attitudes about ethical situations typically encountered by in-home counselors. However, when conducting a multiple regression exclusively for in-home counselors, none of the independent variables predicted attitudes about ethical situations typically encountered by in-home counselors. 


\section{CHAPTER FIVE}

\section{DISCUSSION}

The results of this study are presented in this chapter. Overall, no statistically significant differences were found between in-home and outpatient counselors in attitudes regarding ethical situations encountered by in-home counselors. Furthermore, the independent variables of this study did not predict in-home and outpatient counselors' attitudes regarding ethical situations encountered by in-home counselors. The subsequent sections will examine these results in greater depth. The first section discusses the descriptive data pertaining to the outcome variable (self-reported attitudes of in-home and outpatient counselors regarding ethical situations typically encountered by in-home counselors). The second section presents the results of the study pertaining to the first research question, differences between in-home and outpatient counselors' attitudes about ethical situations typically encountered by in-home counselors. The third section discusses results of the study related to research question two, the degree that the independent variables predict in-home and outpatient counselors' attitudes regarding 
ethical situations typically encountered by in-home counselors. The fourth section discusses results of the study related to research question three, the degree that the independent variables predict in-home counselors' attitudes about ethical situations typically encountered by in-home counselors. The fifth section discusses the open-ended comments provided by participants from Section III of the survey. The sixth section discusses the limitations of the study and closes with implications for counselors, counselor educators, areas for future research, and a summary.

\section{Discussion of Findings From Descriptive Data}

A review of the descriptive statistics from the 21 ethical situations shows several interesting trends. First, the vast majority of items (17 out of 21 ) had a value less than 3. The value 3 equates to Ethical Under Some Conditions. It appears that most participants (both in-home and outpatient counselors) believed these situations typically encountered by in-home counselors are more unethical than ethical. However, it is also worth noting that every single item had the maximum range of 4 , meaning that for every item there was a respondent who scored the item as a 1 (Never Ethical) and another respondent who scored the same item a 5 (Always Ethical). These findings lend support to the amorphous and uncertain nature of ethical situations with in-home counseling.

As stated in Chapter 4, item number 1-"Providing a snack item for a client (e.g., a candy bar, soda, or a pack of gum) for which the counselor is not reimbursed)"-had a mean score of $M=3.35$, which equates to more than "Ethical Under Some Conditions." It is not too surprising that this item was considered more ethical, since it involves the counselor giving something to the client, as opposed to the client giving something to the 
counselor. Furthermore, the item is noticeably small in monetary value, and coupling this with the typical lower income population served by in-home counselors, it makes sense for counselors to believe this would be a compassionate and ethical gesture.

Item number 8 , “telling a client or a client's family member to apply for needed services (e.g., applying for food stamps, applying for a psychiatric or medical evaluation, etc.)" had the highest mean score, and was the only item whose mean was higher than 4 $(M=4.04)$. This item speaks to the case management responsibilities that in-home counselors usually assume. While it is not uncommon for case managers to be so directive, counselors might hesitate to provide such advice.

Interestingly, with regard to the percentage providing counseling compared to case management, both the majority of in-home $68 \%$ and outpatient $60 \%$ counselors reported their distribution of work as $75 \%$ providing counseling and $25 \%$ providing case management services. One would understand this differentiation in tasks for in-home counselors, but many would assume that outpatient counselors generally provide $100 \%$ counseling and $0 \%$ case management services, which was not the case. When viewing the high mean value of item number 8 in light of the fact that all counselors in the study provide some case management, it is not surprising that both in-home and outpatient counselors do not possess significant qualms over actively linking and directing clients to needed services.

Item number 20, "Continuing to provide counseling to a client after it becomes apparent that the client has a serious problem (e.g. schizophrenia, major depression,) for which you have not been trained to provide services or treatment" had the lowest mean, $(M=1.60), M=1.64$ for in-home and $M=1.51$ for outpatient, where $1=$ Never Ethical 
and 2 = Ethical Under Rare Conditions. The concept of working within one's level of competency appears to be very salient for both in-home and outpatient counselors. Furthermore, the mean response did not increase significantly when discriminating between counselors who possessed a graduate degree $(M=1.55)$ and those who had an undergraduate degree or less $(M=1.71)$. It is reassuring to note that even with a minimum education, counseling practitioners are still sensitive to the idea of working within one's level of competency.

As stated in Chapter 4, item number 17, "not being a member of a professional association in counseling or related field" had the largest standard deviation, $(S D=$ 1.509), along with a mean, $(M=3.18)$ and median, $M d n=3(3=$ Ethical Under Some Conditions), thus the item had the largest disagreement among respondents. This finding is not surprising given that the ethical situation relates to both in-home and outpatient counseling, making it susceptible to a wider scope of interpretation. Furthermore, inhome counseling does not have a specific division of ACA or any other professional counseling organization, even though it is a separate and distinctive counseling modality. As a result, the importance of being a member of a professional association relative to inhome counseling appears to be speculative at best.

When viewing the ranked item means, an interesting trend emerged. For the lower ranked items, those with means between 1 and 2 ("Never Ethical" and "Ethical Under Rare Conditions"), initially it seemed surprising that item 14 "consoling a distraught client by cradling or holding him or her" $(M=1.96)$, had eight other items ranked lower (i.e. less ethical). In a profession where physical and sexual boundary violations are widely recognized as the most unethical, one may have expected this item 
to be ranked much lower. However, an explanation may be found when viewing the lower ranked items in light of the ACA Code of Ethics Section A.5. and its charge to avoid ethical situations unless "the interaction is potentially beneficial to the client" (A.5.c.). The lowest ranked items involved situations that would make it difficult to ever justify any benefit to the client. The two lowest items, number $13(M=1.35)$ and $20(M$ $=1.60$ ) involved counseling while impaired and counseling beyond one's scope of competence. Additionally, item $16(M=1.78)$ was the fourth lowest ranked and involved counseling a client while someone not in the immediate family was within hearing distance. Item $4(M=1.90)$ was also ranked lower than item 14 and involved talking to family members and friends about the client, who have no professional role in the case. For all of these items, it is difficult to imagine scenarios where it would be helpful to the client to engage in these situations. Conversely, while holding or cradling a client is still seen as generally inappropriate, the respondents may have envisioned scenarios, while rare, in which such physical contact may benefit the client.

The trend of evaluating and contrasting ethical situations in light of potential benefits and anticipated consequences to the client appeared to continue throughout the range of responses. When viewing the mean responses from approximately 2.00 and above, higher responses are associated with more benign anticipated consequences. Examples include giving a client a ride, (item 2, $M=1.98$ ) providing advice to clients and family members (items $11, M=2.44$ and $19, M=2.81$ ), eating a meal with a client and their family (item 15, $M=2.31$ ), providing a snack to the client (item 1, $M=3.35$ ) and not being a member of a professional association (item $17, M=3.18$ ). While many of 
these items diverge from the therapeutic treatment, they may be perceived as not inflicting direct harm to the client, and so scored as more ethical.

In summary, for the means of the lower ranked items, approximately between 1 and 2 respondents appeared to focus more on whether these items could ever be beneficial to the client. In contrast, for the means of the higher ranked items, approximately between 2 and 4, it appeared that respondents focused more on how harmful or benign the anticipated consequences of these situations could be.

\section{Discussion of Findings From Research Question 1}

The independent samples t-test computed between the two groups of in-home counselors $(n=71)$ and outpatient counselors $(n=37)$ revealed no statistically significant differences in attitudes regarding ethical situations encountered by in-home counselors. Although this is contrary to my hypothesis, a further examination of the population sampled may provide further illumination on this subject. As stated earlier, the majority of both in-home and outpatient counselors possessed master's degrees. This is contrary to what was postulated since the minimum education requirements to provide in-home counseling is a high school diploma while the minimum requirements for most outpatient counselors is a master's degree. Additionally, the population sampled are all licensed by the Department of Behavioral Health and Developmental Services. Many of the agencies that were surveyed provided both in-home and outpatient counseling services. None of the agencies that were contacted were private practitioners of exclusively outpatient counseling services. This information suggests that the outpatient counselors and inhome counselors may have worked in concert with one another, thus participating in 
active communication, supervision, and training with each other. One might conclude that attitudes of in-home and outpatient counselors regarding ethical situations would be more similar if working in the same agency since both groups adhere to the same policies, ascribe to the same mission and philosophy, and have opportunities to communicate with one another.

Furthermore, $72 \%$ of outpatient counselors reported providing in-home counseling in the past, with the number of years ranging from 1 to 13 . This provides further support that the outpatient counselors who were surveyed were not considerably different from in-home counselors regarding attitudes of ethical situations, particularly because at one point in time most of them were in-home counselors.

\section{Discussion of Findings From Research Question 2}

Research question 2 sought to examine the degree that the independent variables (gender, modality, degree, years of experience of a mental health professional, licenses and certifications held, and percentage of work providing counseling compared to case management) predict in-home and outpatient counselors' attitudes about ethical situations typically encountered by in-home counselors. The results showed that only the variable $25 \%$ counseling, $75 \%$ case management, a level of the variable counseling compared to case management, significantly predicted in-home and outpatient counselors' attitudes regarding ethical situations encountered by in-home counselors $(t=-1.987, p=0.05)$. Counselors with more case management duties saw questionable situations as more unethical than counselors with less case management duties. In interpreting these findings, caution is warranted given the overall weakness of the model. However, it is 
interesting to note the uniqueness of the group of respondents who provide $25 \%$ of their time counseling and $75 \%$ doing case management activities. Since counseling and case management are two distinct services with arguably very different roles, boundaries, and treatment philosophies (Williams \& Swartz, 1998), it follows that leaning more towards a case management modality would equate to different views towards ethical situations than its counseling counterpart.

\section{Discussion of Findings From Research Question 3}

Research question 3 sought to examine the degree that the independent variables predict in-home counselors' attitudes about ethical situations typically encountered by inhome counselors. The results showed that none of the variables significantly predicted in-home counselors' attitudes regarding ethical situations encountered by in-home counselors. Given the relatively homogeneous nature of the participants sampled along the dimensions of gender ( $71 \%$ female), degree (61\% held a master's degree), and percentage providing counseling compared to case management $(66 \%$ described their work as consisting of $75 \%$ counseling and $25 \%$ case management), it is not too surprising that these variables did not predict attitudes regarding ethical situations with in-home counseling. Furthermore, due to the methodology of the design, it was impossible to determine the actual number of agencies that participated. Although 21 directors of different agencies agreed to forward the survey to their counselors, it is likely that less than 21 different agencies participated in the actual study. Some agencies had as few as 5 counselors and some had over 200 counselors. Because this study did not monitor which 
agencies the participants came from, it is not possible to determine exactly how alike or different the respondents are. Although not probable, it is still possible that the 108 participants came from only a few different agencies, thus adding to their homogeneity.

\section{Discussion of Findings from Comments on Section III}

The open-ended responses from participants concerning their own personal experiences regarding ethical issues observed while providing in-home counseling yielded valuable data. The responses confirmed the salience of several of the items that were on the survey as it pertains to in-home counseling. Furthermore, responses did not all point to unethical actions initiated by clients (e.g., intoxicated parents, clients asking to borrow money, etc.), but also commented on perceived ethical violations initiated by counselors and supervisors (e.g., counselors disclosing too much personal information to clients, inadequate supervision, incompetent counselors, etc.).

The most frequently mentioned items in this section pertain to unqualified counselors and a lack of competent supervision.

- "I believe the biggest issue currently is that many in-home therapists may only have a bachelors degree, and are terribly unqualified to provide counseling."

- "We see a lot of private agencies doing mentoring rather than therapeutic activities with kids- recreational outings, trips to the mall, etc."

- "People in positions of authority in the agency often have zero direct service experience as a residential counselor and have no idea how client-centered programs are run." 
- "I have observed a lack of adequate preparation and supervision of in-home counselors."

- "I have seen supervisors who have less clinical experience than workers."

- "I have seen counselors given cases they were not clinically qualified to handle. Have seen counselors given inadequate supervision."

Two respondents from rural communities commented on the difficulty of providing inhome counseling to clients who do not have relationships with one another.

- "It is almost impossible NOT to see people who have connections to each other. Ethical guidelines about such situations have a clear urban bias."

- "Small community leading to natural ongoing relationships w/clients following termination of services."

While none of these comments result in statistically significant quantifiable data, the information is useful in gathering recent first-hand reports of current ethical situations that both confirm what previous research has demonstrated, and provide direction for topics of further study. Consequently, issues identified in the open comments section of the survey will be discussed in more detail in the last section concerning areas for future research.

\section{Limitations}

When interpreting the results of this study, several limitations should be considered. According to Creswell (2009) there exist several threats to internal validity that may compromise the generalizability of a study. One threat to this study is that of selection, which occurs when participants are selected who "have certain characteristics 
that predispose them to have certain outcomes" (Creswell, 2009, p. 163). Since the participants were recruited by contacting agency directors and supervisors, the pool of clinicians whom the supervisors recruit may possess special characteristics that may skew the data. Because I left it up to the directors to market and promote the survey, it is difficult to say what message they relayed to their counselors, resulting in less control and consistency. Several directors said they would tell their counselors about the survey opportunity during their team meetings, which of course was not scripted. This may have affected which counselors participated in the survey and whether these respondents possessed any particular characteristics beforehand that would predispose them to responding in a certain way.

Another significant limitation to this study was that the survey instrument has yet to be validated. However, the extensive research throughout the literature and previous ethical surveys (Milliken \& Neukrug, 2009; Roberts, 2006) have contributed to the development of the items. In addition, professionals in the field reviewed the instrument for content validity. A pilot study was completed to field test the survey instrument and complete statistical analyses to determine whether any problems existed prior to completing the actual study. Another limitation was that of social desirability. Participant responses may not have been congruent with their actual attitudes. They may have responded in a manner that they believed was how society would prefer that they respond. It is also possible that participants may not have responded to some of the situations due to not understanding them. As a result, some items may have been skipped or not have reflected accurate attitudes. 
An additional limitation is the homogeneity of the population of in-home and outpatient counselors who participated. The majority of respondents shared several traits (e.g., possessed master's degrees, were female, and provided a similar ratio of counseling to case management). Concerning the two groups of in-home and outpatient, many of the agencies provided both in-home and outpatient counseling services, and as a result, the participants from each group may have interacted, consulted, and participated in training with one another. Furthermore, $72 \%$ of the outpatient counselors surveyed had provided in-home counseling in the past. In light of this, it is not surprising that these two groups did not possess significantly different attitudes regarding ethical situations encountered by in-home counselors. Related to this issue of homogeneity is the number of agencies that participated. As stated earlier, while 21 agencies agreed to forward the survey to their counselors, there is no way to determine the actual number of agencies that participated in this study. This can be seen as quite a significant limitation since participants from only several agencies can hardly be considered generalizable findings. Lastly, this study used a convenience sample and not a random sample. Due to the limited population that was being sampled and the difficulty involved in getting participation, randomizing was not feasible.

\section{Delimitations}

A Delimitation of this study consisted of the population that was surveyed. All participants were either in-home or outpatient counselors who currently work in agencies in the state of Virginia, and as such fall under the restrictions of the Virginia Department of Behavioral Health and Developmental Services. Consequently, the results may not be 
generalizable to unlicensed agencies that provide in-home and outpatient counseling services in Virginia.

\section{Implications for Counselors, Educators, and Supervisors}

The results of this exploratory study offer several points to consider for the counseling profession. Results from the second research question revealed that the percentage of counseling compared to case management that counselors provide may predict in-home and outpatient counselors' attitudes regarding ethical situations encountered by in-home counselors. Counselors with more case management duties saw questionable situations as more unethical than counselors with less case management duties. As stated in chapter two, counseling in an office-based setting provides clearer structure and boundaries in a variety of domains compared to in-home counseling and case management services (Slattery, 2005). Historically, mental health professionals have had a difficult time reaching a consensus regarding what constitutes appropriate and inappropriate boundaries for traditional outpatient counselors (Gabbard \& Lester, 1995; Glass, 2003; McWilliams, 2004). One might imagine the greater complexity involved in grappling between the boundaries and ethics of two distinctly separate helping modalities (counseling and case management) intertwined into one (in-home counseling). The results of this study suggests that the two constructs of counseling and case management may predict practitioners' attitudes regarding ethical situations, thus lending importance to properly educating future practitioners on these differences.

Counselor educators may find it beneficial to instruct their students on the differences (with regard to purpose, service delivery, boundaries, and theoretical 
framework) between outpatient counseling and case management services, as well as inhome counseling, which can be thought of as the integration of the latter two. While case management positions are generally occupied by counselors without a graduate degree, it has been demonstrated that many in-home counselors possess a master's degree or higher $(\mathrm{n}=54)$ and it is not uncommon for a graduate student to work part-time as a case manager or in-home counselor while enrolled in a graduate counseling program, furthering the necessity of such discussion.

The scores from item number 20 on the survey suggest counselors' sensitivity to working within their own competency. However, viewing this in light of several concerns raised in Section III regarding unqualified counselors reveals an interesting disparity. While the majority of counselors affirmed the importance of operating within their boundaries of competence, other responses indicated that many in-home counselors are not doing so because of their lack of education and training. Regardless, what can be agreed upon from this data is that competency, level of training, and qualifications are salient issues with regard to in-home counseling. Current supervisors and directors of inhome counseling agencies may benefit from evaluating current training and supervision standards, as well as examining client outcome data as it relates to counselor performance and qualifications. Furthermore, a more formalized partnership between counselor educators and supervisors of in-home counseling agencies should be explored. As previous research has demonstrated (Snyder \& McCollum, 1999), the gap between counselor education programs and in-home counseling practice is significant and both institutions may benefit greatly from one another. An established relationship between counselor education programs and in-home counseling agencies may not only benefit 
students and in-home counselors, but counselor educators and in-home supervisors as well. Creating awareness of gaps in learning, training, and application may equate to more competent and informed counselor educators and in-home counseling supervisors.

The results from item number 17 on the survey suggest a lack of consensus regarding the importance of being a member of a professional association in counseling or related field. One can see how this is relevant to the competency and training topic, as many association conferences provide ongoing training and resources for members. Directors and supervisors might explore greater affiliation with a counseling or related association or division specifically for in-home counseling. The National Organization for Human Services may be an ideal association, as it targets both undergraduate and graduate students for membership, and encompass a diverse range of mental health disciplines.

\section{Areas for Future Study}

The results of this exploratory study provide at least four directions for future research. First, a wider scope of counselors should be surveyed to better capture the attitudes of in-home and outpatient counselors regarding ethical situations with in-home counseling. Further research is still needed to understand what outpatient counselors who have little to no experience with in-home counseling perceive to be ethical with regard to this modality. Additionally, it would behoove future researchers to monitor the total number of agencies that participate in a similar study in order to ensure better representation of each group (in-home and outpatient counselors). Because the majority 
of in-home counselors surveyed possessed master's degrees, stratifying the populations in more equal numbers respective to degrees held may yield more significant results.

Further study is needed regarding the training of in-home counselors, particularly concerning how counselors are taught the distinction between counseling and case management services, when to assume which role, as well as how to manage the boundaries associated with them.

Greater illumination is also warranted regarding the interaction between in-home counseling supervisors and counselor educators. Given that it is the supervisors and counselor educators who instruct students and in-home counselors about ethical practice, it may be helpful to know what attitudes these leaders possess regarding ethical situations encountered by in-home counselors. This type of research may also facilitate a greater understanding regarding the preparation that is needed for graduate students to become effective and competent in-home counselors.

Finally, responses from open-ended comments suggest exploring the interaction between in-home counselors and the type of communities that they serve (rural or urban). Previous research has documented the differences in boundaries between mental health practitioners in rural areas compared to urban areas (Knapp \& Slattery, 2004). Research on the constructs of setting and modality and the interaction between the two may further the understanding of appropriate ethical behaviors in the counseling profession.

\section{Summary}

This survey study explored the attitudes of in-home and outpatient counselors in the commonwealth of Virginia regarding ethical situations typically encountered by in- 
home counselors. The differences between in-home and outpatient counselors' attitudes about ethical situations were also examined. Additionally, nine demographic variables were analyzed to discern if they predicted in-home and outpatient counselors' attitudes about ethical situations typically encountered by in-home counselors. Results showed that there was not a significant difference between in-home and outpatient counselors' attitudes of ethical situations encountered by in-home counselors. Furthermore, of the independent variables, only one variable, $25 \%$ counseling, $75 \%$ case management predicted in-home and outpatient counselors' attitudes about ethical situations typically encountered by in-home counselors. In general, most counselors were in agreement concerning which situations in-home counselor encountered were ethical.

The results from table 3 that describes the item means ranked from lowest to highest revealed an intriguing trend. For the means of the lower ranked items, approximately between 1 and 2 ("Never Ethical" and "Ethical Under Rare Conditions") respondents appeared to focus more on whether these items could ever be beneficial to the client. In contrast, for the means of the higher ranked items, approximately between 2 and 4 ("Ethical Under Rare Conditions" and "Ethical Under Most Conditions"), the items appeared to be those whose anticipated consequences were more benign.

Results of the multiple regression, descriptive statistics and open-ended comments lead to several conclusions. The provision of counseling and case management services with regard to in-home counseling are important constructs in determining the attitudes that counselors hold regarding ethical situations that in-home counselors encounter. Additionally, the qualifications and competence of both in-home counselors and supervisors are salient domains that future research should explore. The level of 
importance that counselors hold in affiliating with a professional association has also been called into question and warrants greater scrutiny. Further research surrounding these constructs are suggested as well as the interaction between in-home counseling supervisors and counselor educators with regard to the attitudes they hold concerning ethical situations related to in-home counseling.

Running head: ATTITUDES OF COUNSELORS

Attitudes of Counselors Regarding Ethical Situations

Encountered by In-Home Counselors

Authors:

Justin D. Lauka, Theodore P. Remley, Jr., and Christine Ward

Old Dominion University 


\begin{abstract}
This survey study explored the attitudes of in-home and outpatient counselors in Virginia regarding ethical situations encountered by in-home counselors. Differences in responses were examined across several variables to identify any relationships among those constructs that are salient to in-home counseling and ethics. Of 108 participants, no significant differences were found between the two groups. One variable was found to predict counselors' responses: the percent counselors provide counseling services compared to case management. The item seen as most ethical involved telling a client to apply for needed services, surprising, given its directive nature that runs counter to the counseling profession. The item seen as least ethical involved providing counseling outside of one's level of competence. Considering this along with several open-ended comments expressing concern over unqualified and under-educated in-home counselors provides important implications for counselors, supervisors, and educators and gives direction for future research.
\end{abstract}




\section{Introduction}

In recent years, the field of mental health has witnessed the proliferation of counseling services provided within the homes of clients (Adams \& Maynard, 2000; Wasik \& Roberts, 1994). Contributing to this demand for in-home counseling services was the passage of the Adoption Assistance and Child Welfare Act of 1980, which emphasized the maintenance of intact and safe families as opposed to the practice that was prevalent at the time of placing children into foster homes (Christensen, 1995; Nelson, Landsman, \& Deutelbaum, 1990). Flowing from this 1980 law has been a rapid emergence of family preservation services, where clinicians provide concrete services and encourage family empowerment while attempting to keep children in the original household, thus hopefully providing the least restrictive treatment possible in a costeffective manner (Wells \& Biegel, 1992).

Today, in-home counseling services are provided by mental health professionals from various backgrounds to treat a wide array of presenting problems, including both mood and psychotic disorders (Kalucy et al., 2003), antisocial behavior (Curtis, Ronan, \& Borduin, 2004), substance abuse (Gruber \& Fleetwood, 2004), and diabetes (Harris \& Mertlich, 2003). While clients most commonly treated are children and adolescents who possess emotional and behavioral disturbances (Liddle et al., 2005; Mattek et al., 2010, Mosier et al., 2001), in-home counseling has also been shown to be a promising treatment with families (Curtis, Ronan, \& Borduin, 2004; Liddle et al., 2005; Yorgason et al., 2005) and older persons (Cabin, 2010; Maxfield \& Segal, 2008). Typically, the population of clients who receive in-home counseling are referred to as multichallenged or multistressed families, and possess multiple problems that are chronic and severe in 
nature (Adams \& Maynard, 2000; Lawick \& Bom, 2008;). In-home counseling has been found to be a cost effective treatment (Crane et al., 2003) reducing hospitalizations and out-of-home placements of children (Yorgason, 2005). Additionally, by providing counseling services to those clients who would either not be willing or able to receive counseling in an office setting, the counseling field is operating as advocates to the vulnerable and marginalized members of society.

Along with the benefits of this rising modality come challenges as well. More specifically, the literature has documented concerns in safety (Christensen, 1995), environmental distractions (Worth, 2004), counselor training and preparation (Adams \& Maynard, 2000; Stinchfield, 2004), and supervision (Lawson, 2005). Families generally engage in very personal activities, conversations, and experiences within the household. Coupling the home environment with the very intimate nature of the counseling relationship can potentially result emotionally charged and problematic situations (Reiter, 2000; Stinchfield, 2004). Pope and Vasquez (2007) noted the inherent power that mental health professionals possess in the counseling relationship, eliciting profound feelings from the client of love, rejection, shame, guilt, approval, dependence, and panic. While these emotions may serve a therapeutic purpose at times, a counselor eliciting these emotions in a client's home may prove to be a foundation for unethical situations to occur. Furthermore, because the practice of in-home counseling is in its infancy stage, there has not been a considerable amount of research conducted on this modality (Thomas, McCollum, \& Snyder, 1999), particularly regarding ethical challenges. Moreover, the minimal requirements and qualifications that are required of inhome counselors present additional concerns. While most in-home counselors possess at 
least a bachelor's degree, the Medical Assistance Programs (Medicaid), which provide reimbursement for in-home services, place the minimum education requirement of an associate's degree with three years experience (DMAS, 2008). The overall lack of education and training of in-home counselors, combined with the very challenging population of clients that are commonly served in their homes, along with the unique environment in which clients are served (in their homes rather than in professional offices), may create conditions in which unethical and dangerous situations could easily occur. All of these items point to the overarching ethical and boundary-related issues that have recently been given considerable attention (Christensen, 1995; Knapp \& Slattery, 2004; Lawson, 2005; Thomas et al., 1999; Woodford, 1999). However, the exact nature of these ethical issues encountered by counselors has not been adequately captured, requiring further scrutiny. The overall lack of required education and training of in-home counselors, combined with the very challenging population of clients that is commonly served in their homes, along the unique environment in which clients are served lends support to significance of such a study. Previous research studies regarding attitudes of ethical situations have been conducted using professional association directories (Roberts, 2006; Worth, 2004), which generally contain members with more advanced degrees than this study planned to include.

\section{Method}

The primary purpose of this study was to explore the attitudes of in-home and outpatient counselors in the commonwealth of Virginia regarding ethical situations typically encountered by in-home counselors. More specifically, this study sought to determine whether any differences exist in responses by counseling modality (in-home, 
outpatient). Additionally, the independent variables gender of counselor, mental health field (social work, counseling, education, psychology, human services, school psychology, clinical psychology, other), degree (high school diploma, associate's degree, bachelor's degree, educational specialist degree, doctoral degree, other), employment status (part-time, full-time), years of experience as an in-home counselor, years of experience as a mental health professional, license and certifications (Licensed Professional Counselor, Licensed Clinical Social Worker, National Certified Counselor, Qualified Mental Health Professional, Certified Substance Abuse Counselor, Licensed Counseling Psychologist, Licensed Clinical Psychologist, Licensed Marriage and Family Therapist, other), and percentage of work providing in-home counseling compared to case management were examined to determine if they were predictors of in-home and outpatient counselors' attitudes about ethical situations typically encountered by in-home counselors. Finally, these variables were also examined to determine if they predicted exclusively in-home counselors' attitudes about ethical situations. Currently, there is no research that captures the attitudes of in-home counselors along the entire spectrum of training and education levels.

\section{Research Design}

This was a non-experimental survey study. The research packet sent to participants included an informed consent form, a personal information form, and the survey instrument. Ethical situations that are salient to the in-home counseling field were presented in the survey and participants were asked to rate the degree to which they believed the situations were ethical or not ethical. Participants were pooled from a crosssectional convenience sample of various counseling agencies in the state of Virginia. 
This type of design collects data of a given population at one point in time and measures differences among groups within the population (Weirsma \& Jurs, 2009). Utilizing the recommendations of Cohen (1992) as a guideline, assuming medium effect size of $0.15, \alpha$ $=.05$, a minimum of 107 participants were determined to be needed for this study.

\section{Survey Instrument}

The survey instrument used in this study contained three sections in addition to an informed consent form that also displayed the approval by an Institutional Review Board (IRB). The first section of the study examined the attitudes of in-home and outpatient counselors regarding ethical situations typically encountered by in-home counselors. This section included 21 ethical situations that in-home counselors may encounter while in the field. Participants were asked to rate these 21 situations regarding the degree to which they believed them to be ethical or not ethical. The responses were rated on a 5-point Likert scale, $(1=$ Never ethical, $2=$ Ethical under rare conditions, $3=$ Ethical under some conditions, $4=$ Ethical under most conditions, and $5=$ Always ethical). For the second section, participants were asked to provide personal demographic information. The final section consisted of an open-ended question concerning other in-home counseling ethical issues the participant may have observed or encountered while providing in-home counseling.

Ten of the 21 survey items generated were adapted from a dissertation by Roberts (2006) who explored the differences between in-home and office-based counselors regarding ethical violations. Roberts' (2006) scale asked participants to rate the frequencies of ethical behaviors they believed other therapists engaged in within a year. His survey was developed from several surveys (Borys \& Pope, 1989; Epstein \& Simon, 
1990; Pomerantz, et al., 1998) and included items measuring four defined spectrums (confidentiality, role confusion, client diffusion, and unintentional witnessing). Roberts (2006) sent his survey to six in-home professionals in the field for validation of the content validity.

Of the remaining 11 items on the survey, two were adapted from a survey developed by Milliken and Neukrug (2009), which is an updated form of Gibson and Pope's (1993) survey administered to National Certified Counselors. One item was modified from the original item "Consoling your client by touching him or her (e.g., placing your hand on his or her shoulder)" (Milliken \& Neukrug, 2009) and changed to "consoling a distraught client by cradling or holding him or her." The remaining nine items were developed from a thorough examination of the peer-reviewed literature that illuminated issues most salient to in-home counseling. These items included issues of safety, witnessing violence, distractions, and participating in non-therapeutic family activities (Adams \& Maynard, 2000; Christensen, 1995; Cortes, 2004; Thomas et al., 1999; Wasik \& Bryant, 2001). To establish validity, this initial list of items was sent to an expert panel of in-home professionals and experts in the counseling field. The expert panel included directors, clinicians, and researchers. Following the expert review, a pilot study was conducted with 20 participants. A preliminary exploratory factor analysis was performed to determine if scale items were appropriate for inclusion in the instrument. Resulting from the feedback by expert reviewers of the instrument, feedback from counselors who participated in the pilot study, and discussions with the research team, a final version of the instrument was created. 


\section{Participants}

The directors of 96 agencies licensed by the Department of Behavioral Health and Developmental Services (DBHDS) in Virginia were asked by either phone or email to distribute the survey in this study to counselors employed in their agency. Of the 96 agencies contacted, 21 directors agreed to forward the survey to their counselors. The directors that were contacted were also asked to provide the number of counselors that worked at their agency. Because not every director provided the number of counselors working at the agency, and the possibility that the survey was forwarded to other agencies, the response rate is only an approximation. From the information provided, approximately 821 counselors were asked to complete the survey. Of the 821 counselors to whom the survey was sent, 120 responded $(\mathrm{N}=120)$, equating to a response rate of $14.8 \%$.

Data were first screened for univariate outliers. No univariate outliers were identified. Data were screened for univariate normality using Levene's test of homogeneity of variances. Levene's test was not significant for all variables at $p=.05$. The independent variable Employment Status had a split of $83 \%$ for full-time and $17 \%$ for part-time and because of the severe split between the levels of this dichotomous variable, it was omitted from the study.

Data were then screened for multivariate outliers. Mahalanobis' distance was computed. None of the cases exceeded the critical chi-square value of 27.89 . However, upon calculating Mahalanobis Distance for each respective modality (in-home and outpatient), one in-home case was identified as an outlier. Consequently, the case was deleted. 
Next, multivariate normality and linearity were examined by way of scatterplot matrix. The scatterplot matrix revealed shapes that are close to elliptical. Additionally, multivariate homoscedasticity was examined by way of residual plots. The residual plots were also close to elliptical, indicating that the assumption of multivariate normality and linearity was not violated.

Table 1 below displays the demographic information of the 108 participants upon completion of data screening.

Table 1

Participant Demographic Information

Frequency Percent

Gender

Female

Male

Modality

In-home

71

66

Outpatient

Degree Earned

Associate's Degree or Less

Bachelor's Degree

Master's Degree 
Doctoral Degree

Licenses and Certifications Held

Qualified Mental Health Professional

54

Licensed Clinical Social Worker

Professional Counselor

Other Mental Health Provider
Percentage of Counseling Compared to Case Management

100\% Counseling, $0 \%$ Case Management

75\% Counseling, 25\% Case Management

50\% Counseling, 50\% Case Management

25\% Counseling, 75\% Case Management

$0 \%$ Counseling, $100 \%$ Case Management

\section{Results}

\section{Descriptive Data}

Outcome data consisted of the participants' responses regarding ethical situations on a Likert scale from 1 to $5(1=$ Never ethical, $2=$ Ethical under rare conditions, $3=$ Ethical under some conditions, $4=$ Ethical under most conditions, and $5=$ Always ethical). Table 3 displays the means and standard deviations of each item, beginning from lowest mean to highest. All of the 21 items had the maximum range of 4 , meaning that for every item there was a respondent who scored the item 1 (Never Ethical) and another 
respondent who scored the same item 5 (Always Ethical). Table 2 below provides the 21 items in ranked order of means.

Table 2

Attitudes of Counselors Regarding Ethical Situations
Combined

Modalitie In-Home Outpatient $\mathrm{s}$

13. Continuing to provide counseling even though you
are in a state of fear for your personal safety and
subsequently distracted from the session
20. Continuing to provide counseling to a client after it
becomes apparent that the client has a serious problem
(e.g., schizophrenia, major depression) for which you
have not been trained to provide services or treatment

7. Purchasing items from a client or a client's family member (e.g., raffle tickets for a church fundraiser, Girl Scout cookies, etc.)

16. Providing counseling to the client while someone not in the family (e.g., neighbor, houseguest, relative) is within hearing distance

3. Visiting, calling, or sending email messages to a client or a client's family member after termination

5. Accepting an invitation from a client to attend a personal event (e.g. Christmas dinner, hospital visitation for a family member who is ill, etc.)

4. Talking to your friends or your family members who have no professional role in the case about the situation of a client or a client's family members without revealing identifying information

10. Providing individual counseling to a relative, friend, or significant other of a current client or of a client's family member.

$\begin{array}{ccc}1.90 & 1.82 & 2.05 \\ (1.12) & (1.00) & (1.31)\end{array}$

14. Consoling a distraught client by cradling or holding him or her.

$\begin{array}{ccc}1.93 & 1.93 & 1.92 \\ (1.03) & (1.02) & (1.06) \\ & & \\ 1.96 & 1.90 & 2.08 \\ (.95) & (.91) & (1.01)\end{array}$


2. Giving a client or client's immediate family member a ride in your car to do an errand that is not related to the

client's therapeutic goals (e.g., to the bank or grocery store)

6. Disclosing details of a personal nature (e.g., your own health problems, future employment concerns, family

history issues, etc.) to a client or a client's family member

15. Eating a meal with a client or a client's family member when an invitation is offered

21. Providing counseling to a minor when his or her parents or guardians are not at home

18. Providing counseling to a client in a public location where privacy cannot be guaranteed (e.g., coffee shop, park, or library)

11. Answering questions regarding non-therapeutic

think is the best place to get a car loan?" "Could you tell me how to set up my DVD player?")

9. Counseling a client in the client's bedroom to minimize distractions during the counseling session

19. Providing advice that is requested by a client about how to help an individual whom the client knows who has a mental health problem (e.g., "I have a friend who I think is Bipolar, how can I help her?")

17. Not being a member of a professional association in counseling or related field

12. Observing or acquiring direct evidence that a client the criminal activities to law enforcement authorities

1. Providing a snack item for the client (e.g., a candy bar, soda, or pack of gum) for which the counselor is not

8. Telling a client or a client's family member to apply 


\section{Research Question 1}

Research question 1 asked, "What is the difference, if any, between in-home and outpatient counselors' attitudes about ethical situations typically encountered by in-home counselors?"

The null hypothesis for research question 1 stated, "There is no significant difference between in-home and outpatient counselors' attitudes about ethical situations typically encountered by in-home counselors."

To answer the first research question, an independent sample $t$-test was conducted to determine if there was a difference between in-home and outpatient counselors' attitudes about ethical situations typically encountered by in-home counselors. Results revealed that there was not a significant difference in the scores for in-home $(M=2.33$, $S D=.42)$ and outpatient $(M=2.22, S D=.43)$ responses; $t(106)=1.231, p=.221$. The results of this analysis failed to reject the null hypothesis for this research question.

Additionally, independent t-tests were conducted for of each of the 21 ethical situations on the survey to determine if there was a difference between in-home and outpatient counselors' responses to each item. Only the item "Observing or acquiring direct evidence that a client or his or her family members are involved in criminal activity (e.g., selling drugs in the house) and reporting the criminal activities to law enforcement authorities" was found to be statistically significant with regard to the scores for in-home $(M=3.48, S D=1.34)$ and outpatient $(M=2.84, S D=1.42)$ responses; $t(106)=2.309, p$ $=.023$. These results suggest that in-home counselors believed this item to be more ethical than outpatient counselors.

\section{Research Question 2}


Standard multiple regression was conducted to determine whether the independent variables gender, modality, degree, years of experience of a mental health professional, licenses and certifications held, and percentage of work providing counseling compared to case management are predictors of in-home and outpatient counselors' attitudes about ethical situations typically encountered by in-home counselors.

The null hypothesis for this question stated that the above variables would not significantly predict in-home and outpatient counselors' attitudes about ethical situations typically encountered by in-home counselors.

A standard multiple regression was conducted to determine whether the variables predicted in-home and outpatient counselors' attitudes about ethical situations typically encountered by in-home counselors, as measured by participants' overall scores on attitudes of ethical situations questionnaire. Four of the independent variables were dummy coded because they had more than two levels (degree, mental health field, licenses and certifications held, and counseling compared to case management). Multicollinearity among predictor variables was examined by viewing tolerance levels and Variance Inflation Factors (VIF) for each variable. In this model, three levels of three variables were excluded due to high tolerance levels: counseling $75 \%$ and case management $25 \%$ and master's degree.

The standard multiple regression analysis indicated that the overall model did not significantly predict attitudes of counselors regarding ethical situations encountered by in-home counselors, $F(12,90)=.622, p=.818$. A summary of the regression coefficients reveals that only one independent variable significantly contributed to the prediction of 
this model: $25 \%$ counseling, $75 \%$ case management $(t=-1.987, p=0.05)$. Regression coefficients are presented in Table 4.

The results of the regression model failed to reject the null hypothesis; there is no statistically significant finding in the overall model of the demographic variables predicting in-home and outpatient counselors' attitudes about ethical situations typically encountered by in-home counselors. However, as shown in Table 3, one independent variable, $25 \%$ counseling and $75 \%$ case management, significantly contributed to the prediction of this model.

\section{Research Question 3}

For the third research question, standard multiple regression was also conducted to determine whether the independent variables are predictors of in-home counselors' attitudes about ethical situations typically encountered by in-home counselors.

The null hypothesis for this question stated that the above variables would not significantly predict in-home counselors' attitudes about ethical situations typically encountered by in-home counselors.

This question was analyzed using multiple regression to determine whether the variables significantly predict in-home counselors' $(n=66)$ attitudes about ethical situations typically encountered by in-home counselors, as measured by participants' overall scores on the attitudes of ethical situations questionnaire. Multicollinearity among predictor variables was examined by viewing tolerance levels and Variance Inflation Factors (VIF) for each variable. In this model, three levels of three variables were excluded due to high tolerance levels: counseling $75 \%$ and case management $25 \%$, and master's degree. 
The standard multiple regression analysis indicated that the overall model did not significantly predict attitudes of counselors regarding ethical situations encountered by in-home counselors, $F(11,54)=.323, p=.977$. A summary of regression coefficients presented in Table 5 indicated that one of the variables significantly contributed to the model.

The results of the regression model failed to reject the null hypothesis; there is no statistically significant finding in the overall model of the demographic variables predicting in-home counselors' attitudes about ethical situations typically encountered by in-home counselors.

\section{Respondent Comments}

Section III of the survey instrument asked participants to comment on their own personal experiences regarding ethical issues they have observed while providing inhome counseling. Of the 108 complete responses, 41 participants provided comments in Section III. Several participants stated that they had encountered situations similar to the items listed on the survey. These items included the following: observing illegal activities performed by clients, family visitors arriving unexpectedly, having clients contact their counselor after termination, having a meal with a client, counselors being invited to birthday parties and events, counselors not being competent to handle certain client cases, working in a client's home despite feeling unsafe, and counselors disclosing too much personal information to clients.

Ethical situations that were reported and not mentioned in the survey included the following: inadequate supervision, inadequate risk assessment of families, unqualified supervisors, parents intoxicated, clients asking to borrow money, clients providing gifts, 
clients considering counselors as another member of the family, small community resulting in a natural ongoing relationship between client and counselor, counselors with only bachelor's degree and thus being unqualified, donating items to a client in need, and billing issues when two counselors are working in the home.

The most frequently mentioned items in this section pertain to unqualified counselors and a lack of competent supervision.

- "I believe the biggest issue currently is that many in-home therapists may only have a bachelors degree, and are terribly unqualified to provide counseling."

- "We see a lot of private agencies doing mentoring rather than therapeutic activities with kids- recreational outings, trips to the mall, etc."

- "People in positions of authority in the agency often have zero direct service experience as a residential counselor and have no idea how client-centered programs are run."

- "I have observed a lack of adequate preparation and supervision of in-home counselors."

- "I have seen supervisors who have less clinical experience than workers."

- "I have seen counselors given cases they were not clinically qualified to handle. Have seen counselors given inadequate supervision."

\section{Discussion}

A review of the descriptive statistics from the 21 ethical situations shows several interesting trends. First, the vast majority of items (17 out of 21) had a value less than 3 . The value 3 equates to Ethical Under Some Conditions. It appears that most participants (both in-home and outpatient counselors) believed these situations typically encountered 
by in-home counselors are more unethical than ethical. However, it is also worth noting that every single item had the maximum range of 4 , meaning that for every item there was a respondent who scored the item as a 1 (Never Ethical) and another respondent who scored the same item a 5 (Always Ethical). These findings lend support to the amorphous and uncertain nature of ethical situations with in-home counseling.

When viewing the ranked item means, an interesting trend emerged. For the lower ranked items, those with means between 1 and 2 ("Never Ethical" and "Ethical Under Rare Conditions"), initially it seemed surprising that item 14 "consoling a distraught client by cradling or holding him or her" $(M=1.96)$, had eight other items ranked lower (i.e. less ethical) than it. In a profession where physical and sexual boundary violations are widely recognized as the most unethical, one may have expected this item to be ranked much lower. However, an explanation may be found when viewing the lower ranked items in light of the ACA Code of Ethics Section A.5. and its charge to avoid ethical situations unless "the interaction is potentially beneficial to the client" (A.5.c.). The lowest ranked items involved situations that would make it difficult to ever justify the benefit to the client to engage in. The two lowest items, number $13(M=1.35)$ and 20 $(M=1.60)$ involved counseling while impaired and counseling beyond one's scope of competence. Additionally, item $16(M=1.78)$ was the fourth lowest ranked and involved counseling a client while someone not in the immediate family was within hearing distance. Item $4(M=1.90)$ was also ranked lower than item 14 and involved talking to family members and friends about the client, who have no professional role in the case. For all of these items, it is difficult to imagine scenarios where it would be helpful to the client to engage in these situations. Conversely, while holding or cradling a client is still 
seen as generally inappropriate, the respondents may have envisioned scenarios, while rare, in which such physical contact may benefit the client.

The trend of evaluating and contrasting ethical situations in light of potential benefits and anticipated consequences to the client appeared to continue throughout the range of responses. When viewing the mean responses from approximately 2.00 and above, one notices the higher responses are associated with the more benign the anticipated consequences are. Examples of this include giving a client a ride, (item 2, $M=1.98$ ) providing advice to clients and family members (items $11, M=2.44$ and 19, $M=2.81$ ), eating a meal with a client and their family (item $15, M=2.31$ ), providing a snack to the client (item 1, $M=3.35$ ) and not being a member of a professional association (item 17, $M=3.18$ ). While many of these items diverge from the therapeutic treatment, they may be perceived as not inflicting direct harm to the client, and so scored as more ethical than other items.

In summary, for the means of the lower ranked items, approximately between 1 and 2 respondents appeared to focus more on whether these items could ever be beneficial to the client. In contrast, for the means of the higher ranked items, approximately between 2 and 4, it appeared that respondents focused more on how harmful or benign the anticipated consequences of these situations could be.

The independent samples t-test computed between the two groups of in-home counselors $(n=71)$ and outpatient counselors $(n=37)$ revealed no statistically significant differences in attitudes regarding ethical situations encountered by in-home counselors. Although this is contrary to my hypothesis, a further examination of the population sampled may provide further illumination on this subject. As stated earlier, the majority 
of both in-home and outpatient counselors possessed master's degrees. This is contrary to what was postulated since the minimum education requirements to provide in-home counseling is a high school diploma while the minimum requirements for most outpatient counselors is a master's degree.

The open-ended responses from participants concerning their own personal experiences regarding ethical issues observed while providing in-home counseling yielded valuable data. The multiple comments relating to unqualified counselors and supervisors suggest the salience of the constructs of training, competence, and education when providing in-home counseling.

\section{Limitations}

When interpreting the results of this study, several limitations should be considered. According to Creswell (2009) there exist several threats to internal validity that may compromise the generalizability of a study. One threat to this study is that of selection, which occurs when participants are selected who "have certain characteristics that predispose them to have certain outcomes" (Creswell, 2009, p. 163). Since the participants were recruited by contacting agency directors and supervisors, the pool of clinicians whom the supervisors recruit may possess special characteristics that may skew the data.

Another significant limitation to this study was that the survey instrument has yet to be validated. However, the extensive research throughout the literature has contributed to the development of the items, as well as previous ethical surveys (Milliken \& Neukrug, 2009; Roberts, 2006). In addition, professionals in the field reviewed the instrument for content validity. A pilot study was completed to field test the survey instrument and 
complete statistical analyses to determine whether any problems existed prior to completing the actual study. Another limitation was that of social desirability. Participant responses may not have been congruent with their actual attitudes. They may have responded in a manner that they believed was how society would prefer that they respond. It is also possible that participants may not have responded to some of the situations due to not understanding them. As a result, some items may have been skipped or not have reflected accurate attitudes.

An additional limitation was the homogeneity of the population of in-home and outpatient counselors who participated. The majority of respondents shared several traits (e.g., possessed master's degrees, were female, and provided a similar ratio of counseling to case management). Concerning the two groups of in-home and outpatient, many of the agencies provided both in-home and outpatient counseling services, and as a result, the participants from each group may have interacted, consulted, and participated in training with one another. Furthermore, $72 \%$ of the outpatient counselors surveyed had provided in-home counseling in the past. In light of this, it is not surprising that these two groups did not possess significantly different attitudes regarding ethical situations encountered by in-home counselors. Related to this issue of homogeneity is the number of agencies that participated. As stated earlier, while 21 agencies agreed to forward the survey to their counselors, there is no way to determine the actual number of agencies that participated in this study. This can be seen as quite a significant limitation since participants from only several agencies can hardly be considered generalizable findings. 


\section{Implications}

The results of this exploratory study offer several points to consider for the counseling profession. First, results from the first research question revealed that inhome counselors believed it was more ethical to report observed criminal activity than outpatient counselors. This suggests that the ethical and legal matter of mandated reporting may be influenced by the setting that one works in. Consequently, training and discourse on mandated reporting across disciplines and setting may be beneficial. Results from the second research question found that the percentage of counseling compared to case management that counselors provide may predict in-home and outpatient counselors' attitudes regarding ethical situations encountered by in-home counselors. As stated in chapter 2, counseling in an office-based setting provides clearer structure and boundaries in a variety of domains compared to in-home counseling and case management services (Slattery, 2005). Historically, mental health professionals have had a difficult time reaching a consensus regarding what constitutes appropriate and inappropriate boundaries for traditional outpatient counselors (Gabbard \& Lester, 1995;

Glass, 2003; McWilliams, 2004). One might imagine the greater complexity involved in grappling between the boundaries and ethics of two distinctly separate helping modalities (counseling and case management) intertwined into one (in-home counseling). The results of this study suggests that the two constructs of counseling and case management may predict practitioners' attitudes regarding ethical situations, thus lending importance to properly educating future practitioners on these differences.

Counselor educators may find it beneficial to instruct their students on the differences (with regard to purpose, service delivery, boundaries, and theoretical 
framework) between outpatient counseling and case management services, as well as inhome counseling, which can be thought of as the integration of the latter two. While case management positions are generally occupied by counselors without a graduate degree, it has been demonstrated that many in-home counselors possess a master's degree or higher $(n=54)$ and it is not uncommon for a graduate student to work part-time as a case manager or in-home counselor while enrolled in a graduate counseling program, furthering the necessity of such discussion.

The scores from item number 20 on the survey suggest counselors' sensitivity to working within their own competency. However, viewing this in light of several concerns raised in Section III regarding unqualified counselors reveals an interesting disparity. While the majority of counselors affirmed the importance of operating within their boundaries of competence, other responses indicated that many in-home counselors are not doing so because of their lack of education and training. Regardless, what can be agreed upon from this data is that competency, level of training and qualifications are salient issues with regard to in-home counseling. Current supervisors and directors of inhome counseling agencies may benefit from evaluating current training and supervision standards, as well as examining client outcome data as it relates to counselor performance and qualifications. Furthermore, a more formalized partnership between counselor educators and supervisors of in-home counseling agencies should be explored. As previous research has demonstrated (Snyder \& McCollum, 1999), the gap between counselor education programs and in-home counseling practice is significant and both institutions may benefit greatly from one another. An established relationship between counselor education programs and in-home counseling agencies may not only benefit 
students and in-home counselors, but counselor educators and in-home supervisors as well. Creating awareness of gaps in learning, training and application may equate to more competent and informed counselor educators and in-home counseling supervisors.

The results from item number 17 on the survey suggest a lack of consensus regarding the importance of being a member of a professional association in counseling or related field. One can see how this is relevant to the competency and training topic just described, as many association conferences provide ongoing training and resources for members. Directors and supervisors might explore greater affiliation with a counseling or related association or division specifically for in-home counseling. The National Organization for Human Services may be an ideal association, as it targets both undergraduate and graduate students for membership, and encompass a diverse range of mental health disciplines.

\section{Summary}

This survey study explored the attitudes of in-home and outpatient counselors in the commonwealth of Virginia regarding ethical situations typically encountered by inhome counselors. The differences between in-home and outpatient counselors' attitudes about ethical situations were also examined. Additionally, nine demographic variables were analyzed to discern if they predicted in-home and outpatient counselors' attitudes about ethical situations typically encountered by in-home counselors. Results showed that there was not a significant difference between in-home and outpatient counselors' attitudes of ethical situations encountered by in-home counselors. Furthermore, of the independent variables, only one variable, $25 \%$ counseling, $75 \%$ case management predicted in-home and outpatient counselors' attitudes about ethical situations typically 
encountered by in-home counselors. In general, most counselors were in agreement concerning which situations that in-home counselor encountered were ethical.

Results of the multiple regression, descriptive statistics and open-ended comments lead to several conclusions. The provision of counseling and case management services with regard to in-home counseling are important constructs in determining the attitudes that counselors hold regarding ethical situations that in-home counselors encounter. The results from table 3 that describes the item means ranked from lowest to highest revealed an intriguing trend. For the means of the lower ranked items, approximately between 1 and 2 ("Never Ethical" and "Ethical Under Rare Conditions") items appear to be indicative of harmful situations for the client or situations in which there is little or no value to the client. Conversely, items ranked higher, approximately between 2 and 4 ("Ethical Under Rare Conditions" and "Ethical Under Most Conditions"), appeared to be more benign situations that may be interpreted more loosely under ethical guidelines.

Additionally, the qualifications and competence of both in-home counselors and supervisors are salient domains that future research should explore. The level of importance that counselors hold in affiliating with a professional association has also been called into question and warrants greater scrutiny. Further research surrounding these constructs are suggested as well as the interaction between in-home counseling supervisors and counselor educators with regard to the attitudes they hold concerning ethical situations related to in-home counseling. The results of this study also suggest that the attitudes that counselors hold regarding ethical situations common to in-home counselors are similar to each other and congruent with the ACA Code of Ethics (2005). The higher education level of in-home counselor participants in this study (60\% master's 
degree, $11 \%$ doctoral degree) may have contributed to this consensus. Future research with participants from more diverse education levels may reveal significantly different attitudes concerning ethical situations with regard to this modality. 


\section{REFERENCES}

Adams, J. F., \& Maynard, P. E. (2000). Evaluating training needs for home-based family therapy: A focus group approach. American Journal of Family Therapy, 28, 4152.

American Counseling Association. (2005). ACA code of ethics. Alexandria, VA: Author. American Counseling Association. (1997, October 17-19). Definition of professional counseling. Retrieved April 27 $7^{\text {th }}, 2010$, from http://www.counseling.org/Resources

Austin, W., Bergum, V., Nuttgens, S., \& Peternelj-Taylor, C. (2006). A re-visioning of boundaries in professional helping relationships: Exploring other metaphors. Ethics \& Behaviors, 16(2), 77-94.

Babbie, E. (1990). Survey research methods ( $2^{\text {nd }}$ ed.). Belmont, CA: Wadsworth Publishing Company.

Bagdasaryan, S. (2005). Evaluating family preservation services: Reframing the question of effectiveness. Children and Youth Services Review, 27, 615-635.

Bernsen, A., Tabachnick, B. G., \& Pope, K. S. (1994). National survey of social workers' sexual attraction to their clients: Results, implications, and comparison to psychologists. Ethics \& Behavior, 4, 369-388.

Borys, D. S. (1994). Maintaining therapeutic boundaries: The motive is therapeutic effectiveness, not defensive practice. Ethics \& Behavior, 4, 267-273.

Borys, D. S., \& Pope, K. S. (1989). Dual relationships between therapist and client: A national study of psychologists, psychiatrists, and social workers. Professional Psychology: Research and Practice, 20, 283-293. 
Cabin, W. D. (2010). Lifting the home care veil from depression: OASIS-C and evidence-based practice. Home Health Care Management Practice, 22, 171-177.

Carey, K. B. (1998). Treatment boundaries in the case management relationship: A behavioral perspective. Community Mental Health Journal, 34, 313-317.

Christensen, L. L. (1995) Therapists' perspectives on home-based family therapy. The American Journal of Family Therapy, 23, 306-314.

Cohen, J. (1992). A power primer. Psychological Bulletin, 112, 155-159.

Cortes, L. (2004). Home-based family therapy: A misunderstanding of the role and a new challenge for therapists. The Family Journal, 12, 184-188.

Cottrell, D. (1994). Family therapy in the home. Journal of Family Therapy, 16, 189-197.

Crane, R. D., Hillin, H. H., \& Jakubowski, S. F. (2003). Costs of treating conduct disordered youth with and without family therapy. The American Journal of Family Therapy, 33, 403-413.

Creswell, J. W. (2009). Research design: Qualitative, quantitative, and mixed-methods approaches. Thousand Oaks, CA: Sage Publications.

Curtis, N. M., Ronan, K. R., \& Borduin, C. M. (2004). Multisystemic treatment: A metaanalysis of outcome studies. Journal of Family Psychology, 18, 411-419.

Denby, R. W., \& Curtis, C. M. (2003). Why special populations are not the target of family preservation services: A case for program reform. Journal of Sociology and Social Welfare, 30, 149-173.

Epstein, R. S., \& Simon, R. I. (1990). The exploitation index: An early warning indicator of violations in psychotherapy. Bulletin of the Menninger Clinic, 54, 450-465. 
Epstein, R. S., Simon, R. S., Kay, R. I., \& Kay, G. G. (1992). Survey results with the exploitation index. Bulletin of the Menninger Clinic, 56, 150-166.

Gibson, W. T., \& Pope, K. S. (1993). The ethics of counseling: A national survey of certified counselors. Journal of Counseling \& Development, 71, 330-336.

Gladding, S. T. (1996). Counseling: A comprehensive examination. Upper Saddle River, NJ: Prentice Hall.

Glass, L. L. (2003). The gray areas of boundary crossings and violations. American Journal of Psychotherapy, 57, 429-444.

Greeson, J. K. P., Guo, S., Barth, R. P., Hurley, S., \& Sisson, J. (2009). Contributions of therapist characteristics and stability of intensive in-home therapy youth outcomes. Research on Social Work Practice, 19, 239-250.

Gruber, K. J., \& Fleetwood, T. W. (2004). In-home continuing care services for substance use affected families. Substance Use \& Misuse, 39, 1379-1403.

Gutheil, T. G., \& Brodsky, A. (2008). Preventing boundary violations in clinical practice. New York: Guilford Press

Gutheil, T. G., \& Gabbard, G. O. (1998). Misuses and misunderstandings of boundary theory in clinical and regulatory settings. American Journal of Psychiatry, 155, $409-414$.

Harris, M. A., \& Mertlich, D. (2003). Piloting home-based behavioral family systems therapy for adolescents with poorly controlled diabetes. Children's Health Care, $32,65-79$.

Herlihy, B., \& Corey, G. (1997). Boundary issues in counseling: Multiple roles and responsibilities. Alexandria, VA: American Counseling Association. 
Huston, C., \& Armstrong, K. (1999). Home visiting family therapy for children at risk. Family Therapy, 20, 41-45.

Kalucy, R., Thomas, L., Lia, B., Slattery, T., \& Norris, D. (2003). Managing increased demand for mental health services in a public hospital emergency department: A trial of 'hospital-in-the-home' for mental health consumers. International Journal of Mental Health Nursing, 13, 275-281.

Kang-Yi, C. D., \& Gellis, Z. D. (2010). A systematic review of community-based health interventions on depression for older adults with heart disease. Aging \& Mental Health, 14, 1-19.

Kitchner, K. S. (1988). Dual relationships: What makes them so problematic? Journal of Counseling \& Development, 67, 217-221.

Knapp, S., \& Slattery, J. M. (2004). Professional boundaries in nontraditional settings. Professional Psychology: Research and Practice, 35, 553-558.

Lay, B., Blanz, B., \& Schmidt, M. H. (2001). Effectiveness of home treatment in children and adolescents with externalizing psychiatric disorders. European Child \& Adolescent Psychiatry, 10, 80-90.

Lawson, G. (2005). Special considerations for the supervision of home-based counselors. The Family Journal: Counseling and Therapy for Couples and Families, 13, 437444.

Lawson, G., \& Foster, V. A. (2005). Developmental characteristics of home-based counselors: A key to serving at-risk families. The Family Journal: Counseling and Therapy for Couples and Families, 13, 153-161. 
Lazarus, A. A. (1994). How certain boundaries and ethics diminish therapeutic effectiveness. Ethics \& Behaviors, 4, 255-261.

Lawick, J., \& Bom, H. (2008). Building bridges: Home visits to multi-stressed families where professional help reached a deadlock. Journal of Family Therapy, 30, 504516.

Liddle, H. A., Dakof, G. A., Parker, K., Diamond G. S., Barrett, K., \& Tejeda, M. (2001). Multidimensional family therapy for adolescent drug abuse: Results of a randomized clinical trial. American Journal of Drug \& Alcohol Abuse, 27, 651688.

Madsen, W. C. (1999). Collaborative therapy with multi-stressed families: From old problems to new futures. New York: The Guilford Press.

Mattek, R. J., Jorgenson, E. T., \& Fox, R. A. (2010). Home-based therapy for young children in low-income families: A student training program. The Family Journal, $18,189-194$.

Maxfield, M., \& Segal, D. L. (2008). Psychotherapy in nontraditional settings: A case for in-home cognitive behavioral therapy with a depressed older adult. Clinical Case Studies, 7, 154-166.

Milliken, T. F., \& Neukrug, E. S. (2009). Perceptions of ethical behaviors: A survey of human service professionals. Human Service Education, 29, 35-48.

Mosier, J., Burlingame, G. M., Wells, M. G., Ferre, R., Latkowski, M., Johansen, J., Petersen, G., \& Walton, E. (2001). In-home, family-centered psychiatric treatment for high-risk children and youth. Children's Services: Social Policy, Research, and Practice, 4, 51-68. 
Nelson, K. E., Landsman, M. J., \& Deutelbaul, W. (1990). Three models of familycentered placement prevention services. Child Welfare, 69, 3-21.

Neukrug, E., Lovell, C., \& Parker, R. (1996). Employing ethical codes and decision making models: A developmental process. Counseling and Values, 40, 98-106.

Neukrug, E., Milliken, T., \& Walden, S. (2001). Ethical complaints made against credentialed counselors: An updated survey of state licensing boards. Counselor Education \& Supervision, 41, 57-70.

Norris, D. M., Gutheil, T. G., \& Strasburger, L. H. (2003). This couldn't happen to me: Boundary problems and sexual misconduct in the psychotherapy relationship. Psychiatric Services, 54, 517-522.

Ponton, R. F., \& Duba, J. D. (2009). The ACA code of ethics: Articulating counseling's professional covenant. Journal of Counseling \& Development, 87, 117-121.

Pope, K. S. (1994). Sexual involvement with therapists. Washington, DC: American Psychological Association.

Pope, K. S., Tabachnick, B. G., \& Keith-Spiegel, P. (1988). Good and poor practices in psychotherapy: National survey of beliefs of psychologists. Professional Psychology: Research and Practice, 19, 547-552.

Pope, K. S., \& Keith-Spiegel, P. (2008). A practical approach to boundaries in psychotherapy: Making decisions, bypassing blunders, and mending fences. Journal of Clinical Psychology: In Session, 64, 638-652.

Pope, K. S., \& Vasquez, M. J. T. (2007). Ethics in psychotherapy and counseling: A practical guide (3rd ed.). San Francisco: Jossey-Bass. 
Provider manual. (2008). In Virginia Department of Medical Assistance Services

(DMAS). Retrieved April 20, 2010, from

http://websrvr.dmas.virginia.gov/ProviderManuals/Default.aspx.

Reamer, F. G. (2003). Boundary issues in social work: Managing dual relationships. Social Work, 48, 121-133.

Reiter, M. D. (2000). Structuring home-based therapy: Four phases to effective treatment. Journal of Family Social Work, 4, 21-34.

Reiter, M. D. (2000). Utilizing the home environment in home-based family therapy. Journal of Family Psychotherapy, 11, 27-39.

Roberts, J. M. (2006). Navigating the ethical quandaries of wraparound multi-systemic treatment (MST): A comparative study between in-home and outpatient therapies. Dissertation Abstracts International. Retrieved December 10, 2009 from ProQuest Dissertation \& Theses (UMI: 3276529)

Slattery, J. M. (2005). Preventing role slippage during work in the community: Guidelines for new psychologists and supervisees. Psychotherapy: Theory, Research, Practice, \& Training, 42, 384-394.

Slesnick, N., \& Prestopnick, J. L. (2004). Office versus home-based family therapy for runaway, alcohol abusing adolescents: Examination of factors associated with treatment attendance. Alcoholism Treatment Quarterly, 22, 3-19.

Snyder, W., \& McCollum, E. E. (1999). Their home is their castle: Learning to do inhome family therapy. Family Process, 38, 229-242.

Sonne, J. L. (1994). Multiple relationships: Does the new ethics code answer the right questions? Professional Psychology: Research and Practice, 25, 336-343. 
Speck, R. V. (1964). Family therapy in the home. Journal of Marriage and Family, 26, $72-76$.

Stinchfield, T. A. (2004). Counselor preparation: Clinical competencies specific to family-based therapy. Counselor Education \& Supervision, 43, 286-300.

Strasburger, L. H., Jorgenson, L., \& Sutherland, P. (1992). The prevention of psychotherapist sexual misconduct: Avoiding the slippery slope. American Journal of Psychotherapy, 46, 544-555.

Swiggart, W., Feurer, I. D., Samenow, C., Delmonico, D. L., \& Spickard, W. A. (2008). Sexual boundary violation index: A validation study. Sexual Addiction \& Compulsivity, 15, 176-190.

Thomas, V., McCollum, E. E., \& Snyder, W. (1999). Beyond the clinic: In-home therapy with head start families. Journal of Marital and Family Therapy, 25, 177-189.

Thompson, S. J., Bender, K., Lantry, J., \& Flynn, P. M. (2007). Treatment engagement: Building therapeutic alliance in home-based treatment with adolescents and their families. Contemporary Family Therapy, 29, 39-55.

Tubbs, P., \& Pomerantz, A. M. (2001). Ethical behaviors of psychologists: Changes since 1987. Journal of Clinical Psychology, 57, 395-399.

Wasik, B. H., \& Bryant, D. M. (2001). Home visiting: Procedures for helping families. Thousand Oaks, CA: Sage.

Wells, K., \& Biegel, D. E. (1992). Intensive family preservation services research: Current status and future agenda. Social Work Research \& Abstracts, 28, 21-28.

Wiersma, W., \& Jurs, S. G. (2009). Research methods in education: An introduction $\left(9^{\text {th }}\right.$ ed.). Boston: Pearson Education. 
Williams, J., \& Swartz, M. (1998). Treatment boundaries in the case management relationship: A clinical case and discussion. Community Mental Health Journal, 34, 299-311.

Woodford, M. S. (1999). Home-based family therapy: Theory and process from "friendly visitor" to multisystemic therapy. The Family Journal, 7, 265-269.

Woodford, M. S., Bordeau, W. C., \& Alderfer, C. (2006). Home-based service delivery: Introducing family counselors in training to the home as a therapeutic milieu. The Family Journal, 14, 240-244.

Worth, J. B. (2004). Home-based therapy: A survey of the attitudes and perceptions of home-based practitioners. Dissertation Abstracts International. Retrieved December 10, 2009 from ProQuest Dissertation \& Theses (UMI: 3135010 ).

Yee, W. C., \& Andrews, J. (2006). Professional researcher or a 'good guest'? Ethical dilemmas involved in researching children and families in the home setting. Educational Review, 58, 397-413.

Yorgason, J. B., McWey, L. M., \& Felts, L. (2005). In-home family therapy: Indicators of success. Journal of Marital and Family Therapy, 31, 301-312. 


\section{Appendix A}

DIRECTIONS

The purpose of this instrument is to measure the attitudes of counselors regarding in-home counselor ethics. Please respond to the items as they apply to inhome counselors. If you are an in-home counselor, simply respond according to your thoughts and perceptions about these items. If you are not an in-home counselor, attempt to put yourself in the place of an in-home counselor and respond accordingly.

\section{Section I: Ethical Situations}

On a scale of 1 to 5 , rate the following counselor behaviors regarding the degree to which you believe the counselor behaviors are ethical or not ethical.

$1 \quad 2 \quad 3 \quad 4 \quad 5$

Never ethical Ethical under Ethical under Ethical under Always rare conditions some conditions most conditions ethical

1. Giving a client or client's immediate family member a ride in your car to do an errand that is not related to the client's therapeutic goals (e.g., to the bank or grocery store).

$\begin{array}{lcccc}1 & 2 & 3 & 4 & 5 \\ \square & \square & \square & \square & \square\end{array}$

2. Providing a snack item for a client (e.g., a candy bar, soda, or a pack of gum) for which the counselor is not reimbursed.

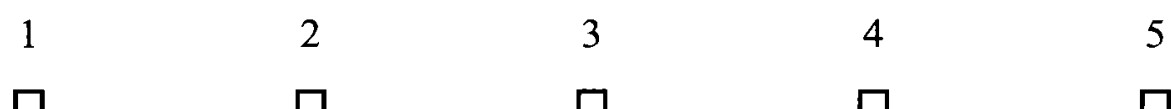

3. Visiting, calling, or sending email messages to a client or a client's family member after termination.

$\begin{array}{lllll}1 & 2 & 3 & 5\end{array}$ 


$\begin{array}{ccccc}1 & 2 & 3 & 4 & 5 \\ \text { Never ethical } & \text { Ethical under } & \text { Ethical under } & \text { Ethical under } & \text { Always } \\ & \text { rare conditions } & \text { some conditions } & \text { most conditions } & \text { ethical }\end{array}$

4. Talking to your friends or your family members who have no professional role in the case about the situation of a client or a client's family members without revealing identifying information.

$\begin{array}{lllll}1 & 2 & 3 & 4 & 5 \\ \square & \square & \square & \square & \square\end{array}$

5. Accepting an invitation from a client to attend a personal and intimate family event (e.g., Christmas dinner, hospital visitation for a family member who is ill, etc.).

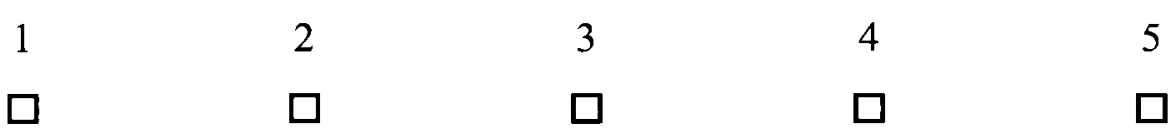

6. Disclosing details of a personal nature (e.g., your own health problems, future employment concerns, family history issues, etc.) to a client or a client's family member.

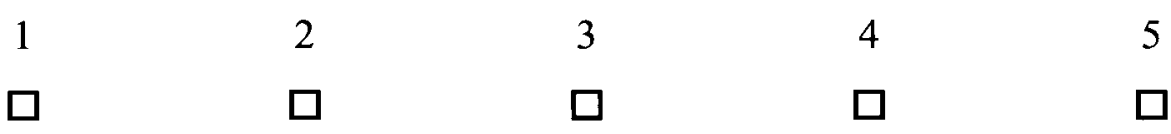

7. Purchasing items from a client or a client's family member (e.g., raffle tickets for a church fundraiser, Girl Scout cookies, etc.).

$\begin{array}{lllll}1 & 2 & 3 & 4 & 5 \\ \square & \square & \square & \square & \square\end{array}$

8. Telling a client or a client's family member to apply for needed services (e.g., applying for food stamps, applying for a psychiatric or medical evaluation, etc.).

$\begin{array}{lllll}1 & 2 & 3 & 4 & 5\end{array}$


9. Counseling a client in the client's bedroom to minimize distractions during the counseling session.

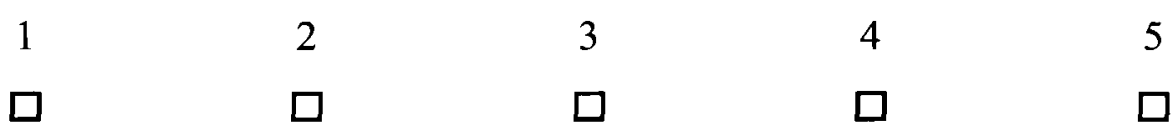

10. Providing individual counseling to a relative, friend, or significant other of a current client or of a client's family member.

1

2

3

4

5

11. Answering questions regarding non-therapeutic issues outside of a counselor's role (e.g., "Where do you think is the best place to get a car loan?" "Could you tell me how to set up my DVD player?").

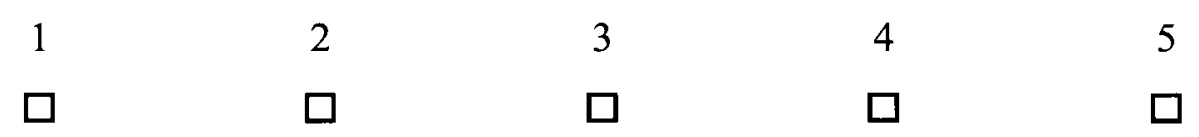

12. Observing or acquiring direct evidence that a client or his or her family members are involved in criminal activity (e.g., selling drugs in the house) and reporting the criminal activities to law enforcement authorities.

$\begin{array}{lllll}1 & 2 & 3 & 4 & 5 \\ \square & \square & \square & \square & \square\end{array}$

13. Continuing to provide counseling even though you are in a state of fear for your personal safety and subsequently distracted from the session. 


$\begin{array}{ccccc}1 & 2 & 3 & 4 & 5 \\ \text { Never ethical } & \text { Ethical under } & \text { Ethical under } & \text { Ethical under } & \text { Always } \\ & \text { rare conditions } & \text { some conditions } & \text { most conditions } & \text { ethical }\end{array}$

14. Consoling a distraught client by cradling or holding him or her.

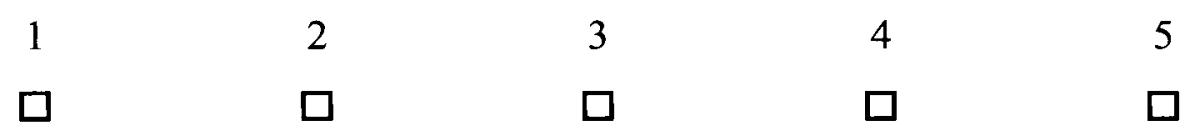

15. Eating a meal with a client or a client's family member when an invitation is offered.

$\begin{array}{lllll}1 & 2 & 3 & 4 & 5 \\ \square & \square & \square & \square & \square\end{array}$

16. Providing counseling to the client while someone not in the family (e.g., neighbor, houseguest, relative) is within hearing distance.

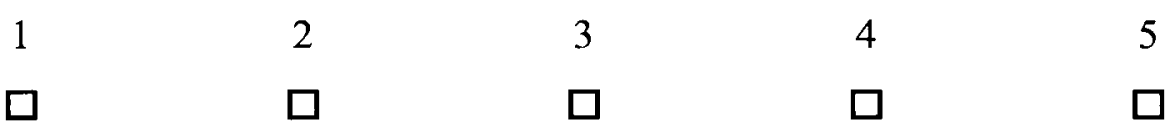

17. Not being a member of a professional association in counseling or a related field.

$\begin{array}{lllll}1 & 2 & 3 & 4 & 5 \\ \square & \square & \square & \square & \square\end{array}$

18. Providing counseling to a client in a public location where privacy cannot be guaranteed (e.g., coffee shop, park, or library).

$\begin{array}{lllll}1 & 2 & 3 & 4 & 5 \\ \square & \square & \square & \square & \square\end{array}$


1

2

3

4

5

Never ethical Ethical under Ethical under Ethical under Always rare conditions some conditions most conditions ethical

19. Providing advice that is requested by a client about how to help an individual whom the client knows who has a mental health problem (e.g., "I have a friend who I think is Bipolar, how can I help her?")

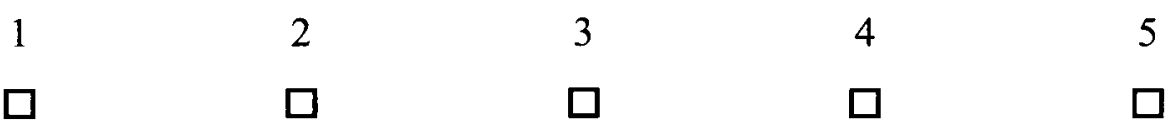

20. Continuing to provide counseling to a client after it becomes apparent that the client has a serious problem (e.g., schizophrenia, major depression) for which you have not been trained to provide services or treatment.

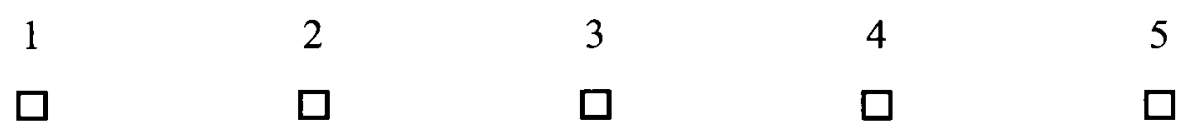

21. Providing counseling to a minor when his or her parents or guardians are not at home.

$\begin{array}{lllll}1 & 2 & 3 & 4 & 5 \\ \square & \square & \square & \square & \square\end{array}$




\section{Section II: Personal Information Form}

Please provide the following information about yourself.

1. What is your gender?
a. Male
b. Female

2. What is the highest level of education you've completed?
a. General Equivalency Diploma
b. High school diploma
c. Associate's degree
d. Bachelor's degree
e. Master's degree
f. Educational Specialist degree
g. Doctoral degree
h. Other (please indicate)

3. For the highest level of education you've completed, what is your degree in?
a. Social Work
b. Counseling
c. Education
d. Psychology
e. Human Services
f. School Psychology
g. Clinical Psychology
h. Other (please indicate)

4. In your current position, where do the majority of the services you provide take place?

a. In-home

b. Outpatient

5. Approximately how many years of experience do you have as an in-home counselor? years

6. Approximately how many total years of experience do you have as a mental health worker or professional? years 
7. Please check all licenses or certifications that you currently have:

a. Licensed Professional Counselor

b. Licensed Clinical Social Worker

c. National Certified Counselor

d. Qualified Mental Health Professional

e. Certified Substance Abuse Counselor

f. Licensed Clinical Psychologist

g. Licensed Counseling Psychologist

h. Licensed Marriage and Family Therapist

i. Other (please indicate)

8. Are you currently employed part-time or full-time?
a. Part-time
b. Full-time

9. Case management is defined as assisting individuals and their families to access services that may be in addition to mental health services such as any medical, nutritional, social, educational, vocational, housing, transportation, leisure, legal and advocacy services that the individual needs to function in a community setting. Counseling is defined as direct verbal interaction with a client, using interventions that address wellness, personal growth, or career development, as well as pathology.

On average, what percentage of your work with clients would you consider to be counseling and what percentage is case management?

a. $100 \%$ counseling \& $0 \%$ case management

b. $75 \%$ counseling $\& 25 \%$ case management

c. $50 \%$ counseling \& $50 \%$ case management

d. $25 \%$ counseling $\& 75 \%$ case management

e. $0 \%$ counseling $\& 100 \%$ case management

Section III: (Optional) Your Comments on Ethical Situations in InHome Counseling

In your experiences as an in-home counselor, please comment below on any ethical issues you have observed or encountered. 


\title{
Appendix B
}

\author{
Informed Consent Letter
}

Greetings,

You are being asked to participate in a research study conducted by Justin Lauka, a Ph.D. candidate under the supervision of Dr. Ted Remley at Old Dominion University in the Department of Counseling and Human Services in Norfolk, VA. The purpose of this study is to explore the attitudes of counselors regarding ethical situations typically encountered by in-home counselors in licensed agencies in the state of Virginia. This study has been approved by Old Dominion University's Institutional Review Board (IRB Number: 200902127).

Since the focus of my study is on counselors in the state of Virginia, I am contacting you to request your participation in this research because you have been identified as a mental health professional who provides either in-home or outpatient counseling from an agency in the state of Virginia.

This study consists of an online survey that will be administered to individual participants. You will be asked to respond to a series of situations that in-home counselors may encounter in the field and rate them on the degree to which you believe the situation to be ethical. Additionally, we ask that you also provide demographic information. Should you decide to participate in this confidential research you may access the anonymous survey by following the web link

https://www.surveymonkey.com/s/3RHNHVW . The survey will take approximately 10 to 15 minutes. In agreeing to participate in this study, you understand that:

a) There are no known physical or psychological risks associated with participation in this study.

b) All data will be kept strictly confidential and no data on individual participants will be reported at any time.

c) All documentation related to this study will be stored in a locked file cabinet in a locked office.

d) Three years after completion of the research project, all records will be destroyed.

e) Participation in this study is voluntary.

f) Refusal or withdrawal will not result in a penalty or loss of benefits of any kind.

g) Your consent can be withdrawn at any time without consequence.

h) You have a right to refuse to participate or discontinue your participation at any time.

The results of this project will be coded in such a way that the respondent's identity will not be attached to the final form of this study. Aggregate data will be presented representing statistical information. All data will be stored in a secure location accessible only to the researcher. Upon completion of the study, all information will be destroyed. Final aggregate results will be made available to participants upon request. Any information gathered from the Demographic Sheet and assessments will be identified only by the given participant code. The results from the data may be used in reports, presentations, and publications, but no identifying information will be used whatsoever. If you have questions or concerns during the time of your participation in 
this study, or after its completion or you would like to receive a copy of the final aggregate results of this study, please contact:

Justin Lauka, M.A., NCC

Old Dominion University

110 Education Building

Norfolk, VA 23529

Phone: 989-992-7307

Email: jlauka@,odu.edu
Dr. Ted Remley

Old Dominion University

110 Education Building

Norfolk, VA 23529

Phone: 757-683-6695

Email: Tremley@,odu.edu

I have read this consent form and I understand what is being requested of me as a participant in this study. I freely consent to participate. The investigator provided me with a copy of this form through email. I certify that I am at least 18 years of age. By clicking on the link below, and completing and submitting this anonymous online survey, I am consenting to participate in this research.

\section{https://www.surveymonkey.com/s/3RHNHVW}




\section{Appendix C}

\section{Follow-Up Letter}

Greetings! This is a reminder regarding an email you may have received two weeks ago asking for your participation in a research project. The deadline for this research is , and your participation is greatly appreciated! To serve as a reminder, the previous email stated the following:

I am a Ph.D. candidate supervised under Dr. Ted Remley at Old Dominion University in the Department of Counseling and Human Services in Norfolk, VA. I am in the data collection process of my dissertation studying the attitudes of counselors regarding ethical situations typically encountered by in-home counselors in licensed agencies in the state of Virginia. This study has been approved by Old Dominion University's Institutional Review Board (IRB Number: 200902127).

Since the focus of my study is on counselors in the state of Virginia, I am contacting you to request your participation in this research because you have been identified as a mental health professional who provides either in-home or outpatient counseling from an agency in the state of Virginia.

This study consists of an online survey that will be administered to individual participants. You will be asked to respond to a series of situations that in-home counselors may encounter in the field and rate them on the degree to which you believe the situation to be ethical. Additionally, we ask that you also provide demographic information. Should you decide to participate in this confidential research you may access the anonymous survey by following the web link https://www.surveymonkey.com/s/3RHNHVW . The survey will take approximately 10 to 15 minutes.

Again, thank you for your time and consideration in participating in this project! All links will remain open until and are the same as in the previous email.

Thank you.

Sincerely,

Justin Lauka, M.A., NCC

Old Dominion University

110 Education Building

Norfolk, VA 23529

jlauka@odu.edu 


\section{CURRICULUM VITAE \\ Justin Douglas Lauka}

Office

Norfolk Community Services Board

225 W. Olney Road

Norfolk, VA, 23507

(757) 823-1627 (telephone)

jlauka@odu.edu (e-mail)
Home

340 Fairfax Avenue, Apt. 1

Norfolk, VA 23507

(989) 992-7307 (cell)

\section{Education}

Ph.D. Candidate, Counselor Education and Supervision, Old Dominion University, Degree Expected in 2011 (CACREP Accredited)

M.A. Community Counseling, Regent University, 2008

(CACREP Accredited)

B.A. Psychology, Michigan State University, 2005

B.A. Finance, Michigan State University, 2004

\section{Credentials}

National Certified Counselor (NCC)

National Board for Certified Counselors

November, 2008 - present

\section{Professional Experience}

$1 / 10$ - Present

Director, ODU/NCSB-Olney Road Counseling Center, Norfolk, Virginia 5/09-12/09

Associate Director, ODU/NCSB-Olney Road Counseling Center, Norfolk, Virginia

\section{Refereed Publications}

Sikes, A., Cole, R. F., McBride, R., Fusco, A., \& Lauka, J. (2009). Addressing the needs of substance abusing adolescents: A guide for professional school counselors. Journal of School Counseling, 7(43). Retrieved from http://www.jsc.montana.edu/articles/v7n43.pdf

\section{Presentations}

McBride, R., \& Lauka, J. (2009, October). Positive and negative aspects of doctoral students supervising master's students in counselor education and supervision programs. Roundtable Presentation at the ACES Annual Conference, San Diego, CA. 